دوال إنتاج وتكاليف محصول القمح وأهم مشاكل زراعته بمحافظة أسيوط عبد الله حلمي عبد الغنى، جلا عبد الفتاح الصغير، سوزان عبد المجيد ابو المجد، يحيى على حسين

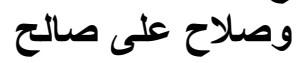

$$
\text { قسم الاقتصاد الزر اعي- كلية الزراعة - جامعة أسيوط }
$$

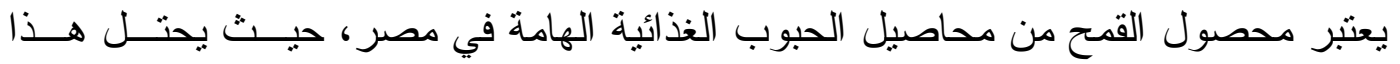

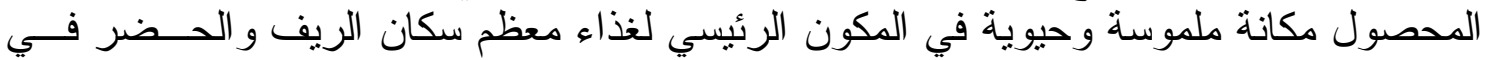

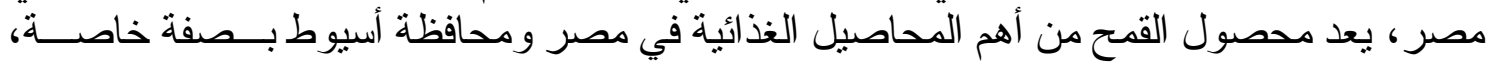

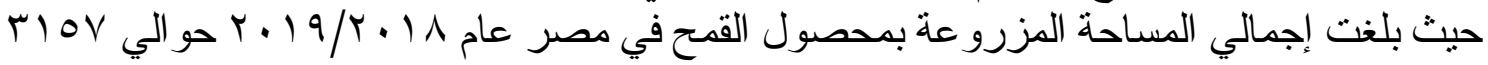

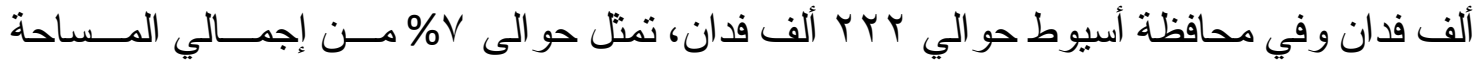

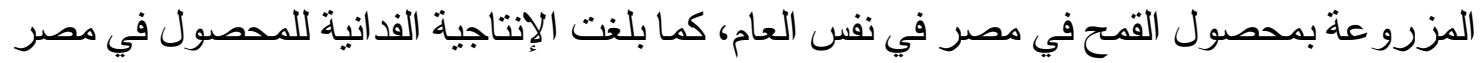

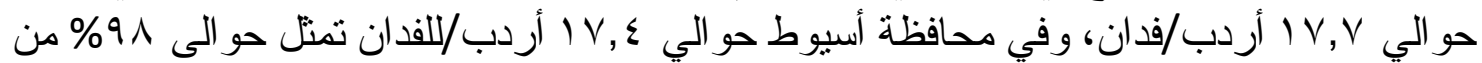

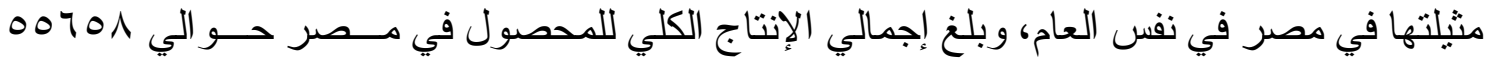

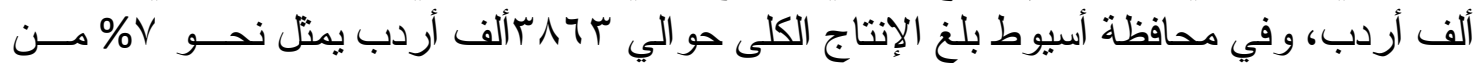

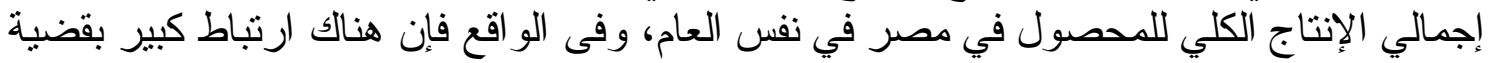

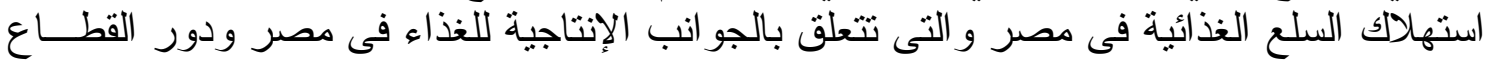

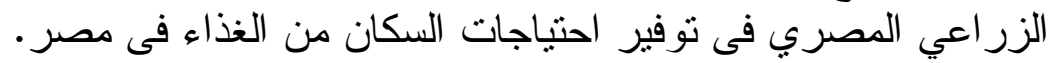
الكلمات الثاله: الإنتاج ، القدح و التنكاليف.

تتمنل المشكلة الرئيسية للبحث في أنه بالر غم من جهود الدولة لزيادة الإنتاج الزر اعي بصفة

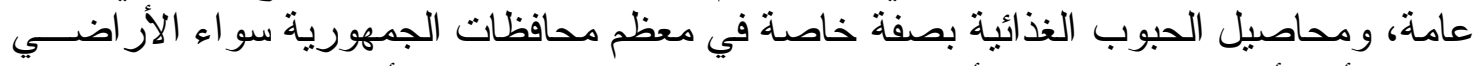

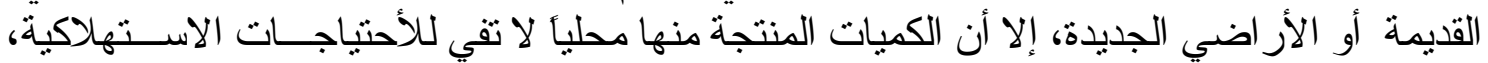

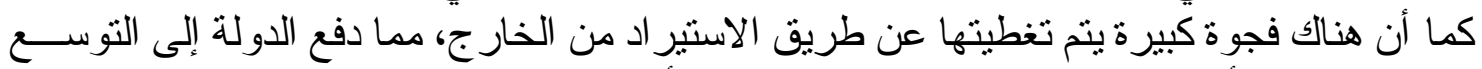

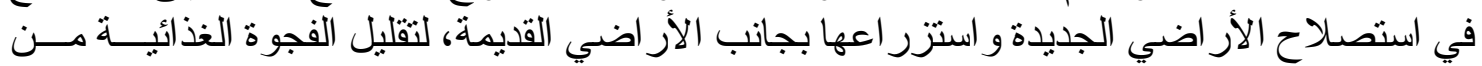
ناحية رفع كفاعة استخدام المو ارد الاقتصادية و الزر اعية المستغلة في زر اعتها من ناحية أخرى. هدف البحث: تاحن تهدف الدر اسة إلى تقدير دو ال إنتاج وتكاليف محصول القمح بمحافظة أسيوط وذللك للتعرف

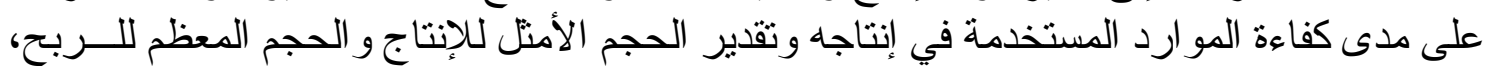

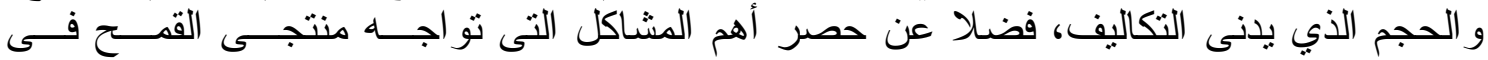
المحافظة.

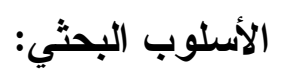

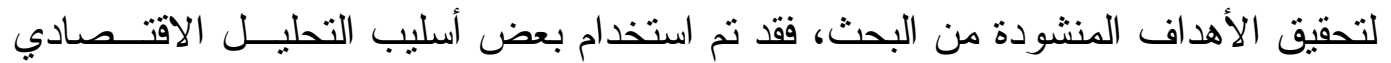

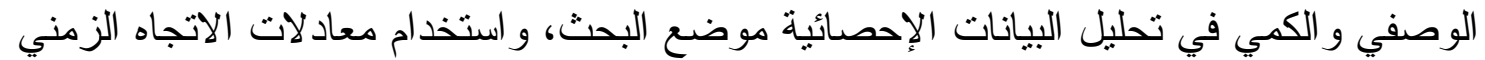

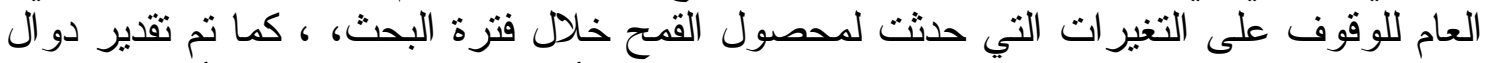

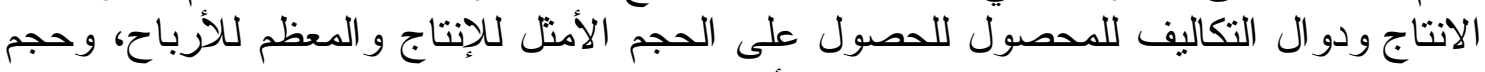

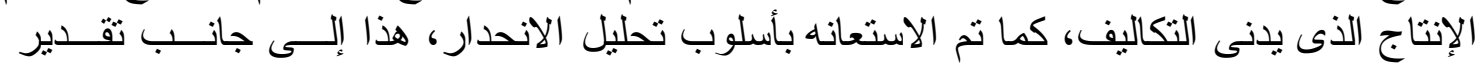


بعض مقاييس الكفاءة الاقتصادية لمحصول القمح بعينة البحث بمحافظة أسيوط للموسم الزر اعى $. r \cdot 19 / r \cdot 11$ مصادر البيانات: - مصات

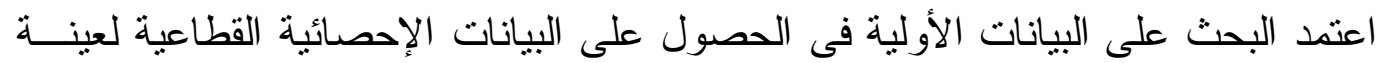

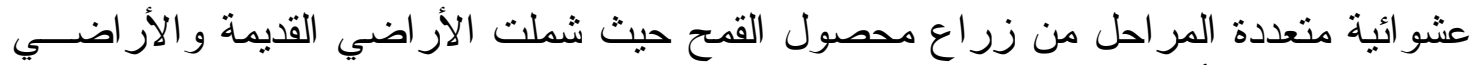

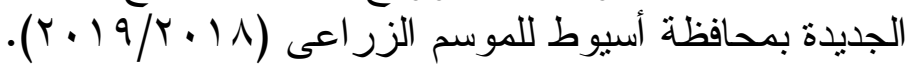
توصيف عينة البحث. في ضوء المبادئ الإحصائية اعتمد البحث في الحصول علي البيانات الأولية علي البيانات

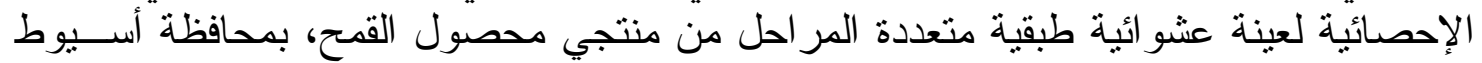

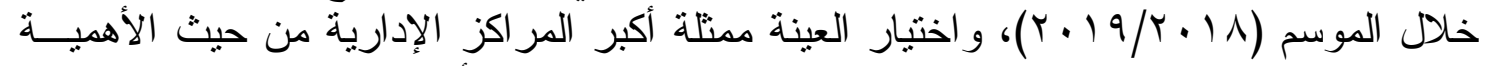

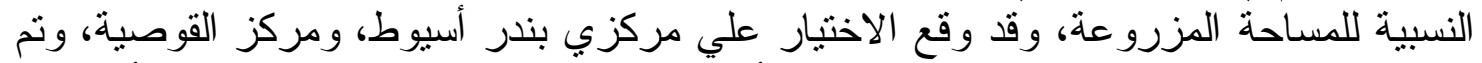

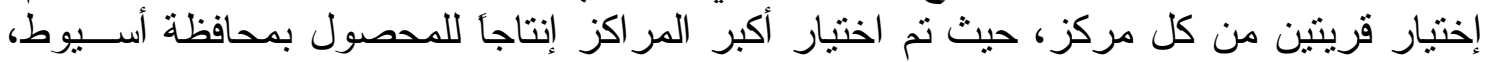

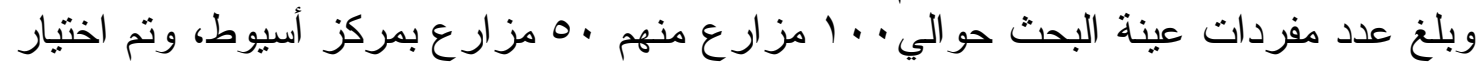

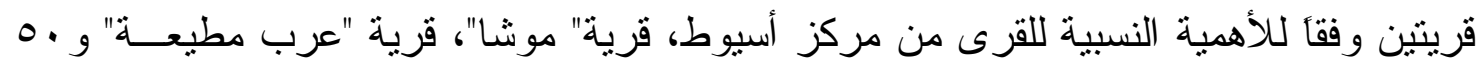

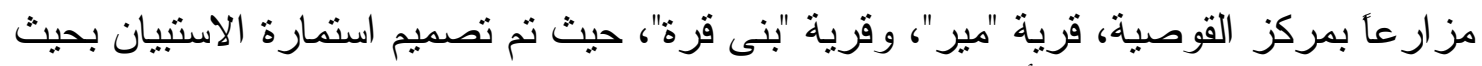

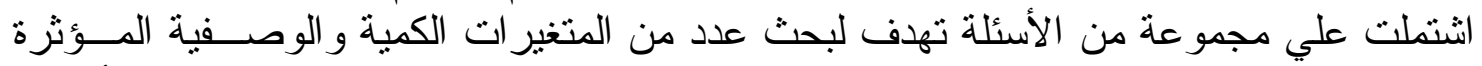

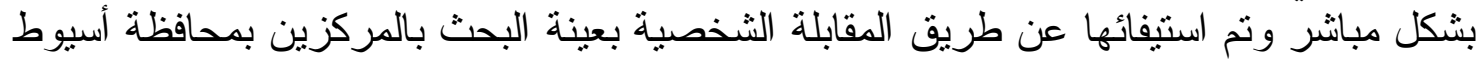

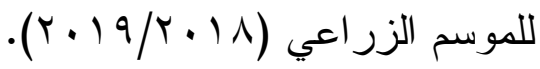

$$
\begin{aligned}
& \text { النتائج البحثية: }
\end{aligned}
$$

أولا: المؤشر ات الإحصائية لأهم عناصر إنتاج محصول القمح فى محافظة أسيوط

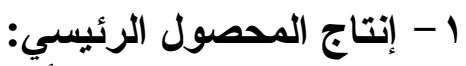

يتضح من الجدول رقم(1)، أن إنتاج الفدان من محصول القمح الرئيسي فى الأر اضي القديمة

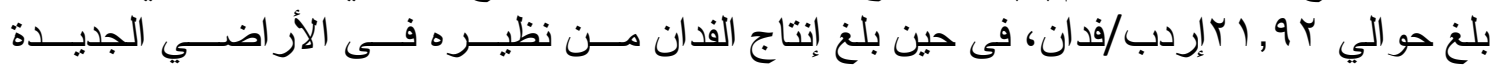

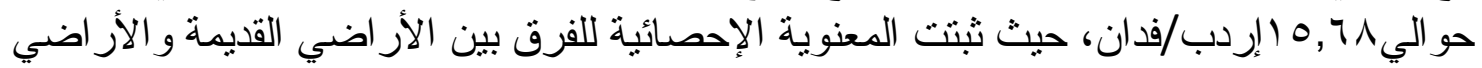

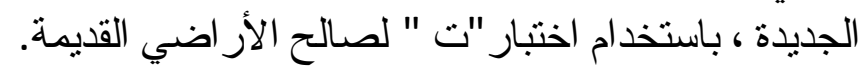

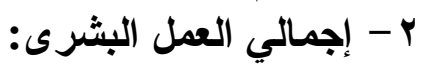

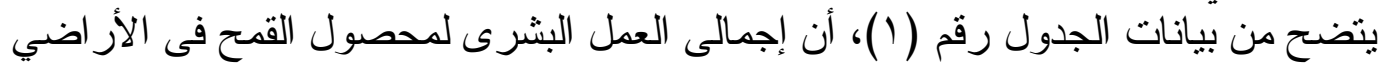

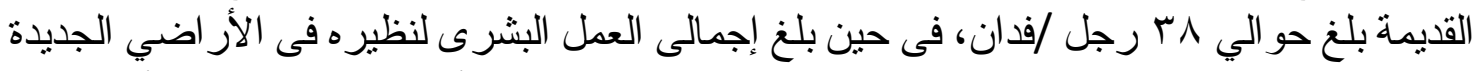

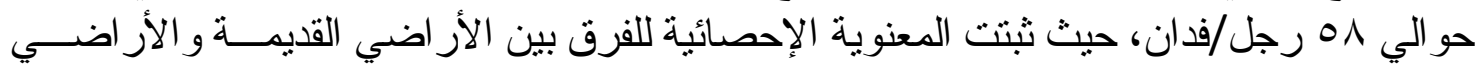

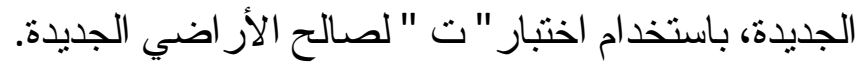

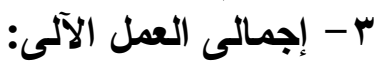

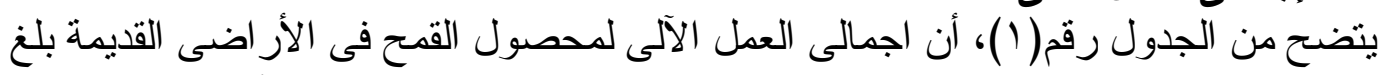

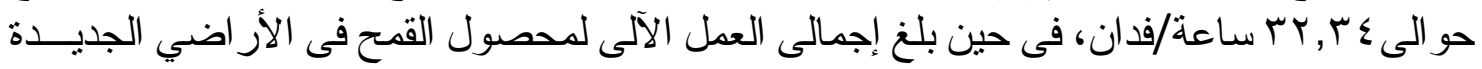

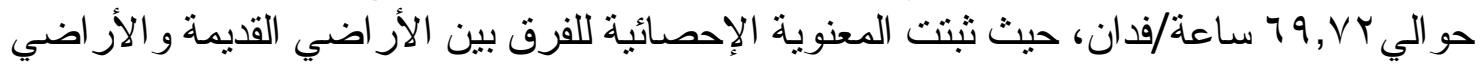
الجديدة، باستخدام أختبار " ت " لصاعة لهالح الأر اضي الجديدة. ع - كمبة التقاوي:

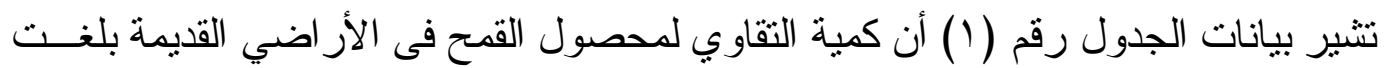

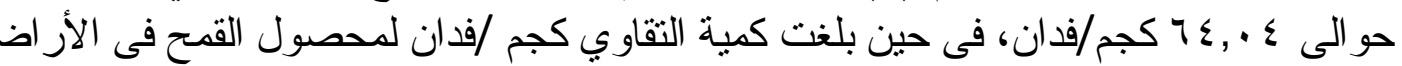


الجديدة حو الى V V, IV كجم/فدان، حيث ثبتث المعنوية الإحصائية للفرق بين الأر اضـــي القديمــة

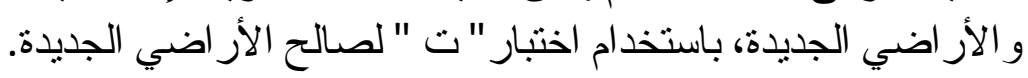

ه - كمية السماد البلادى:

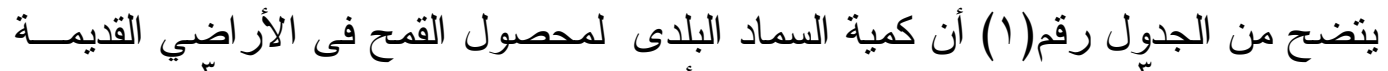

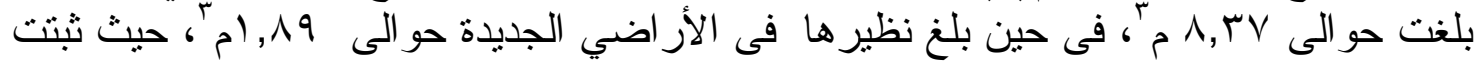

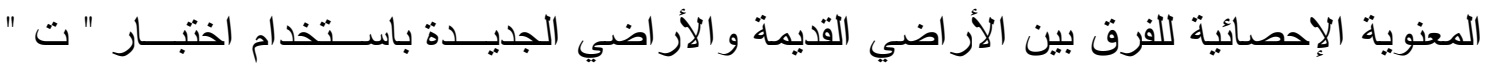
لصالح الأر اضي القديمة.

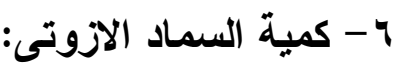

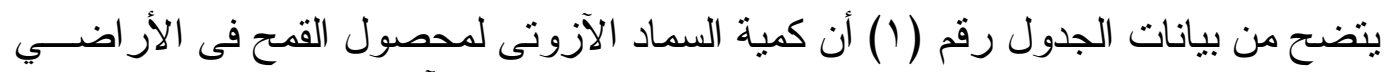

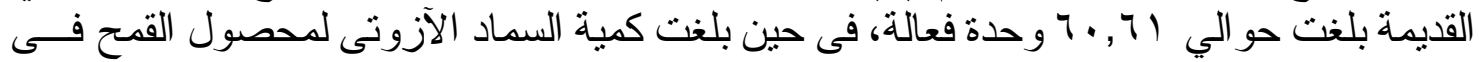

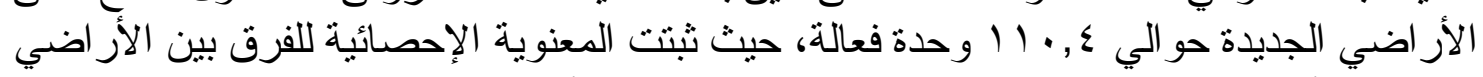

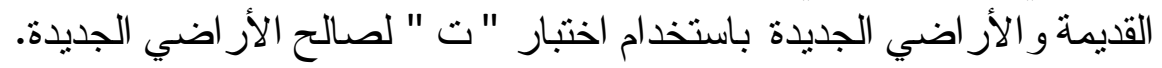

جدول ا ـ بعض المؤشرات الإحصائية لأهم عناصر إنتاج محصول القمح بمحافظة أسيوط خلا موسم

\begin{tabular}{|c|c|c|c|c|c|c|}
\hline \multirow{3}{*}{ t- test } & & & & & & $q / p \cdot 1$ \\
\hline & \multicolumn{2}{|c|}{ أر اضى جليدة } & \multicolumn{2}{|c|}{ أر اضى قديمة } & \multirow[b]{2}{*}{ الوحده } & \multirow[b]{2}{*}{ المتغير ات } \\
\hline & الالحعيارى & المتوسط & الالاحعيارى & المتوسط & & \\
\hline$* * 14, \wedge 4$ & 1,01 & 10,71 & r,भ & rI,qr & اردب & انتاج المحصول الرئيسى \\
\hline$* * 11, .1$ & 9,0 & $\Delta \wedge, \cdots$ & T,YY & $r \wedge$ & عامل & اجمالى عمل \\
\hline$* *$ * $1, Y \leq$ & $q, r \wedge$ & $99, V Y$ & \&,rq & $r Y, \& r$ & ساعه & اجمالى عمل آلى \\
\hline$* * \%, 99$ & $11, \cdot v$ & $v q, I V$ & $\wedge, 97$ & $7 \varepsilon,+7$ & كجم & كمية التقاوي \\
\hline$* * \vee, \vee 1$ & $\varepsilon, \Gamma \leq$ & $1, \wedge 9$ & $r, 10$ & $\Lambda, r V$ & $r_{p}$ & كمية السماد البلادى \\
\hline$* * 9, Y q$ & $Y \wedge, \leqslant \uparrow$ & $11 \cdot, 2$ & $10,7 Y$ & $9 ., 71$ & وحدة فعالة & كمية السماد الازوتى \\
\hline$* * 11,10$ & $1 V, .0$ & $\Delta \theta, \wedge \mu$ & $1 \leq, Y 7$ & 17,79 & وحدة فعالة & كمية السماد الفوسفاتى \\
\hline
\end{tabular}

المصدر : جمعت وحسبت من استمار ات الاستبيان .

\section{- كمية السماد الفوسفاتى: - V}

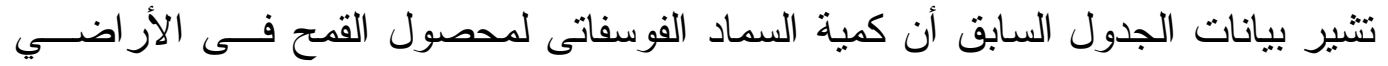

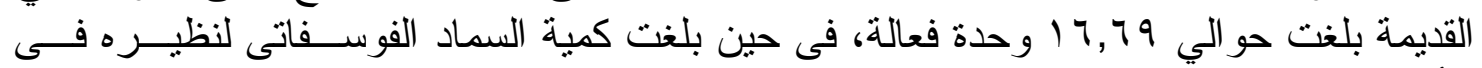

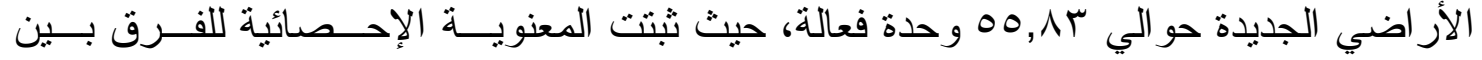
الأر اضي القديمة و الأر اضي الجديدة باستخدام اختبار " ت " لصالح الأر اضي الجديدة.

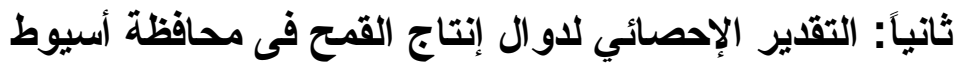

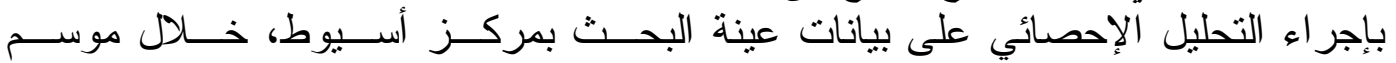

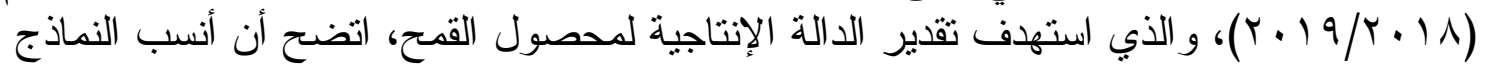

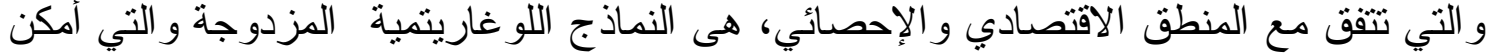

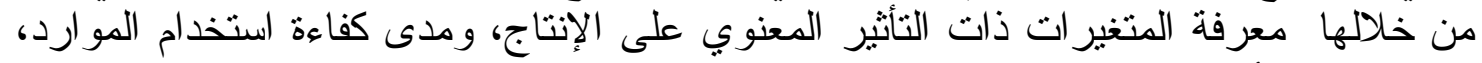

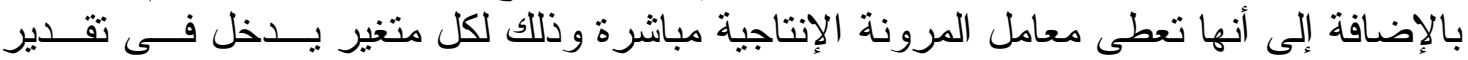




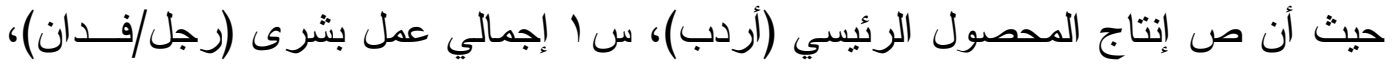

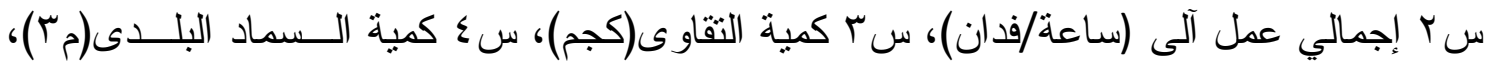

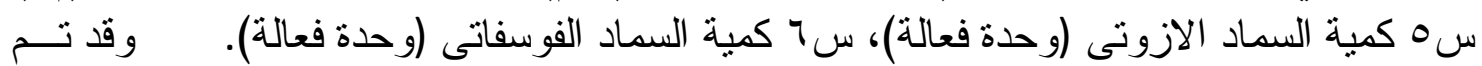

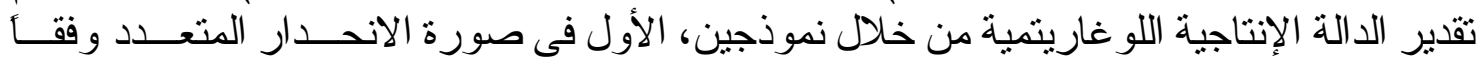

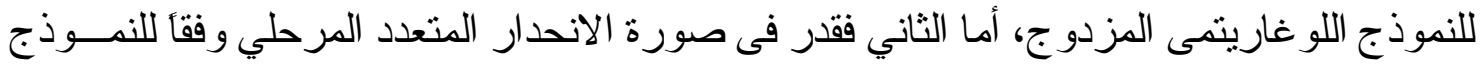
اللو غاريتمى المزدوج، وذلك اللك بالنسبة لأهم العناصر الإنتاجية المستخدمة.

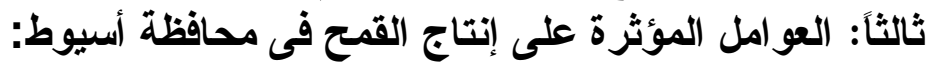

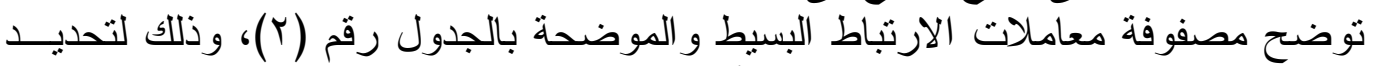

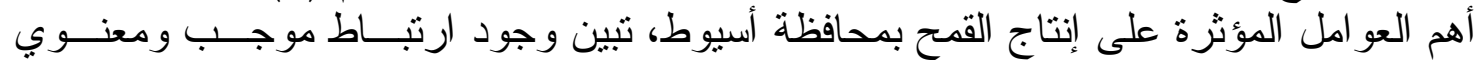

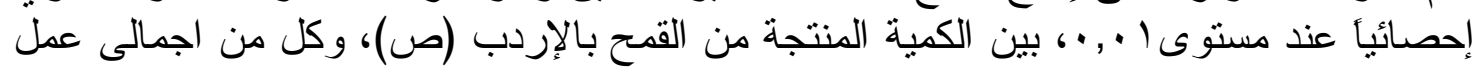

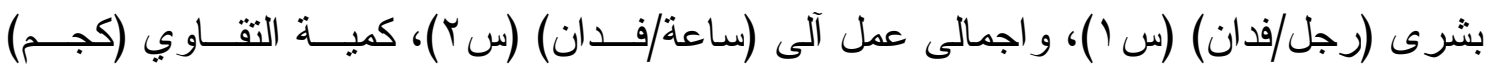

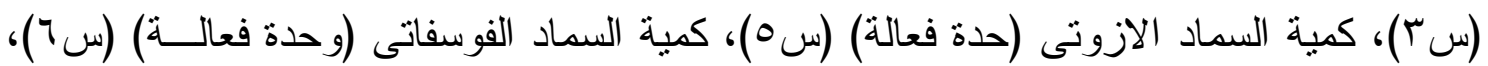

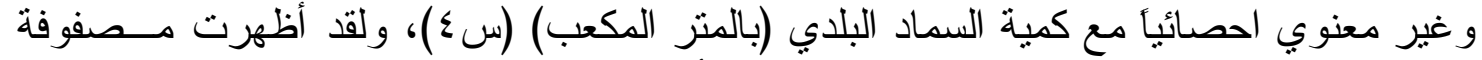

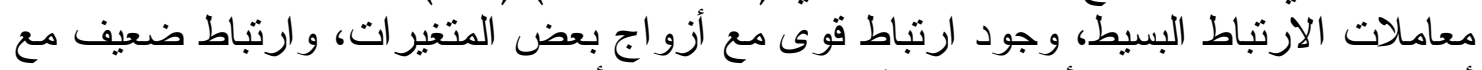

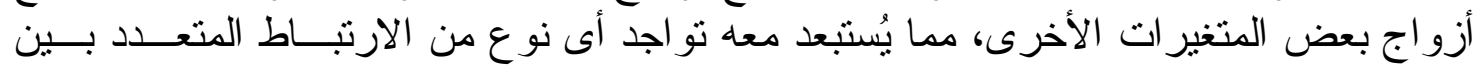

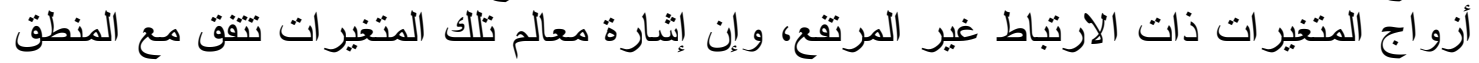

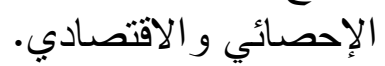

رابعاً: نتائج تقدير دالة الإنتاج ومشتقاتها الاقتصادية فى محافظة أسيوط:

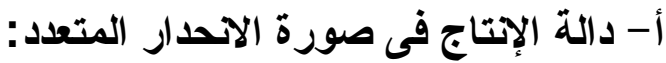

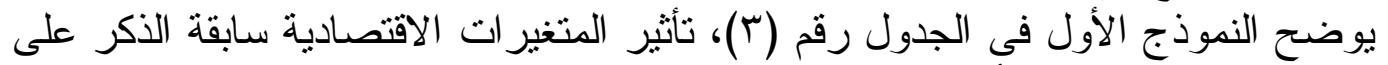

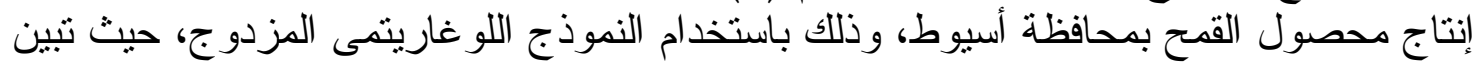

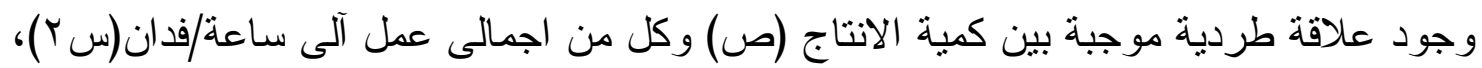

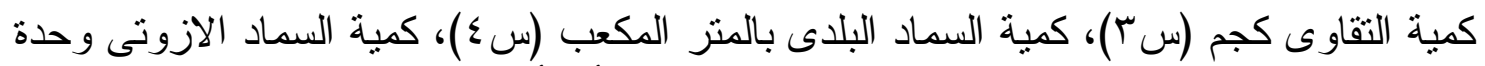

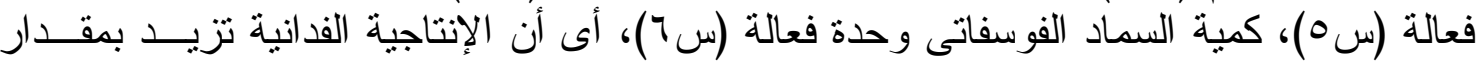
الوحا

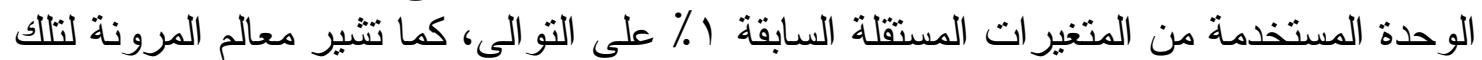

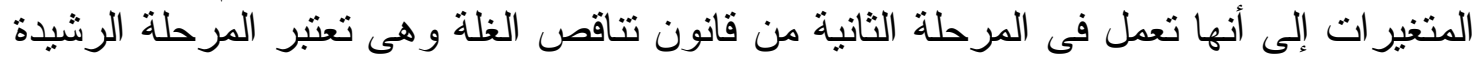

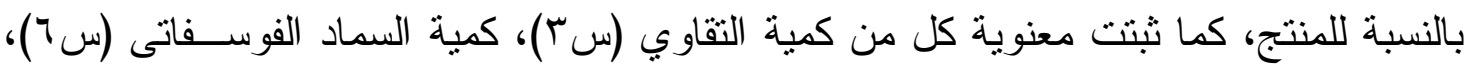

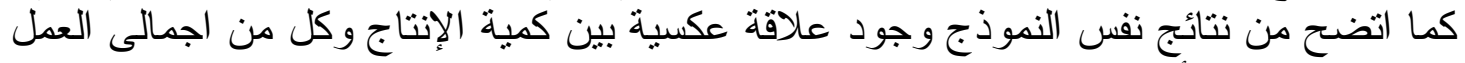

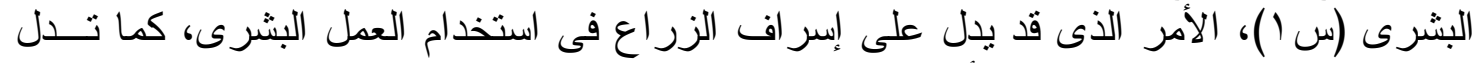

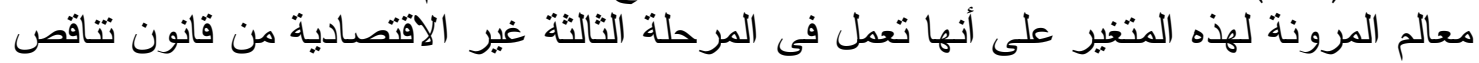

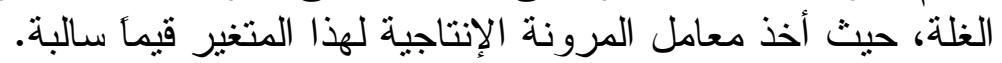

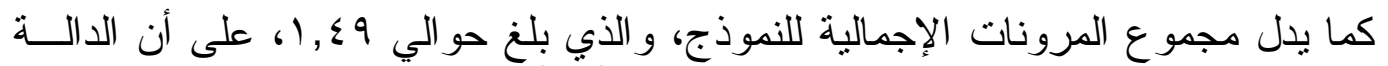

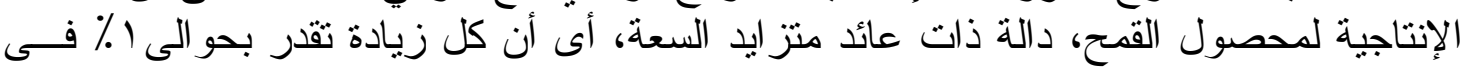

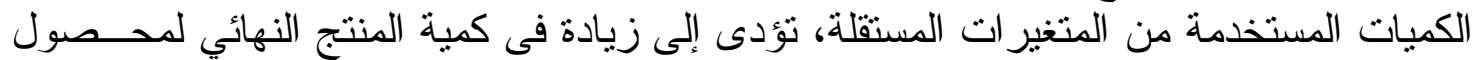

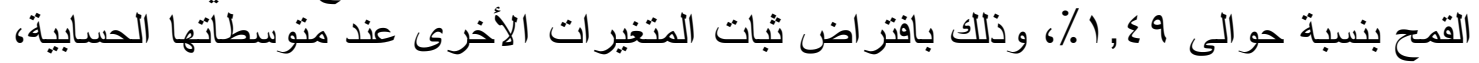

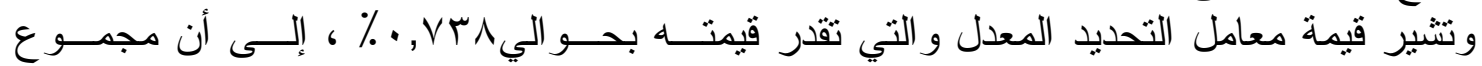

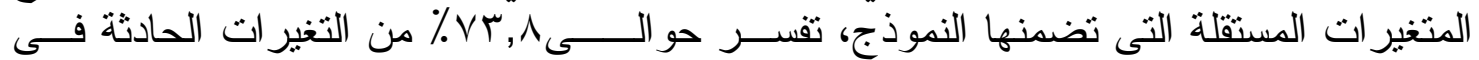

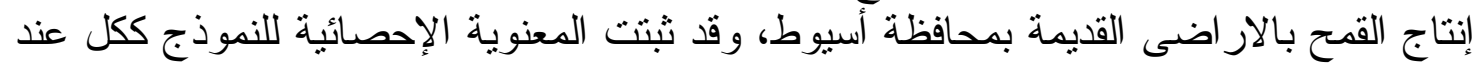

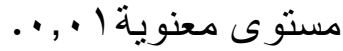


Website:www.aun.edu.eg/faculty_agriculture/journals_issues_form.php E-mail: ajas@aun.edu.eg

جدول r. مصفوفة معاملات الارتباط البسيط لإنتاج محصول القمح فى محافظة أسيوط خــلا موســـ

\begin{tabular}{|c|c|c|c|c|c|c|c|}
\hline 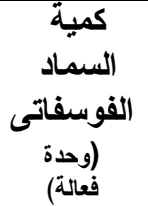 & (الازوتماد & كمية السماد & كمية التقاوى & عمل آلى & اجمالى عمل بشرى & المرصئي & البيان \\
\hline & & & & & & 1 & انتاج المصصول الرئيسى \\
\hline & & & & & 1 & $* *, T \vee T$ & اجمالى عمل بشرى \\
\hline & & & & 1 & $* *, \wedge 07$ & $* *, \vee \vee 9 \wedge$ & اجمالى عمل آلى \\
\hline & & & 1 & $* *, 9 \wedge \mathrm{V}$ & $* *, \wedge \neg Y$ & $* *, \Lambda \cdot r$ & كمية التقاوى (كجم) \\
\hline & & 1 & $\cdot, 141$ & $*, 19$ & $*, \mid \wedge \varepsilon$ & $\cdot, 1 \leqslant v$ & كمية السماد البلدى (بالمتر المكع) \\
\hline & 1 & $*, 190$ & $* *, \wedge \curlyvee \wedge$ & $* *, \wedge \vee \checkmark$ & $* *, \wedge, 0$ & $* *, \vee \vee \neg 1$ & 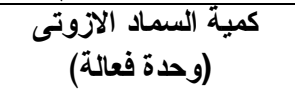 \\
\hline 1 & $* *,, Y q \leq$ & $* *, 011$ & **, •, тчr & **, •, & $* *,, \curlyvee \diamond \wedge$ & $* *, r \mid \wedge$ & كميةّ السماد الفوسفاتى \\
\hline
\end{tabular}

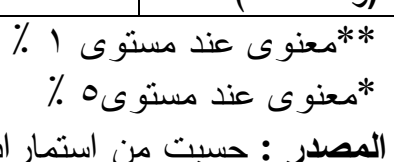

المصدر : حسبت من استمار ات الاستيبان .

جدول r. نتائج تقدير دالة إنتاج فى الصورة اللوغاريتمية المزدوجة لمحصول القمح بمحافظة أسيوط

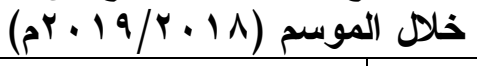

\begin{tabular}{|c|c|c|c|c|}
\hline الإجمالية - المرونة & ف & 2 & المعــــــــــــــــادلة & الم الموذج \\
\hline $1, \leqslant 9$ & $* * 01,7 \varepsilon$ & $\cdot, V \mu^{\prime}$ & 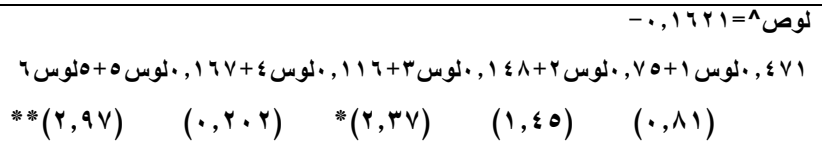 & اللوغاريتمى الكامل \\
\hline $1, \leqslant \pi$ & $* * \| V, r r$ & $\cdot, V Y_{0}$ & 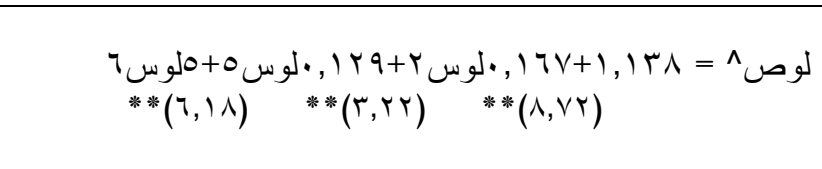 & المزدوج المتئعد الموذد \\
\hline
\end{tabular}

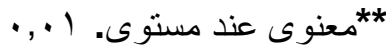

"معنوى عند مستوى 0 ., •.

المصدر : حسبت من بيانات استمار ات الإستبيان.

ب - دالة الإتتاج فى صورة الاحدار المتعدد المرحلى :

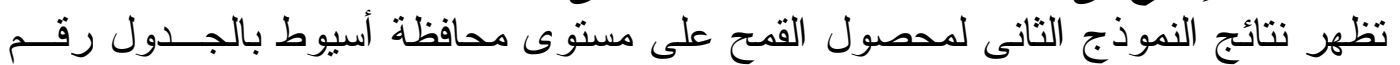

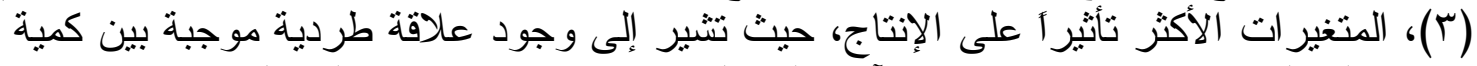

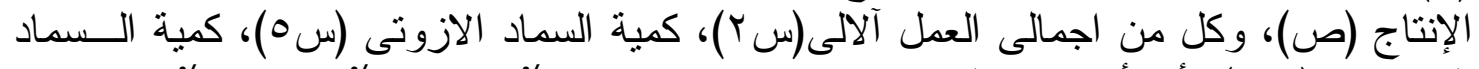

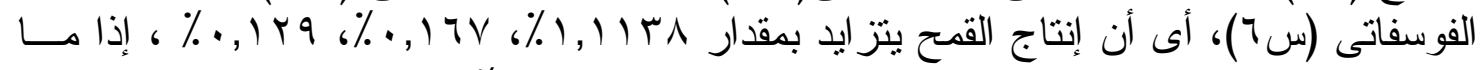

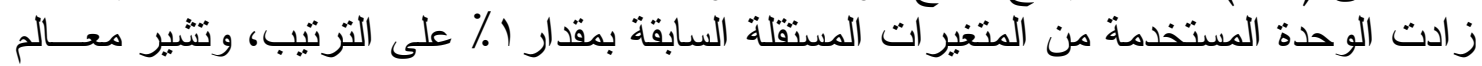

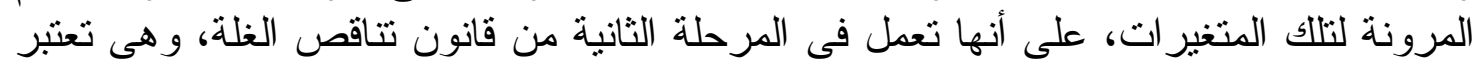

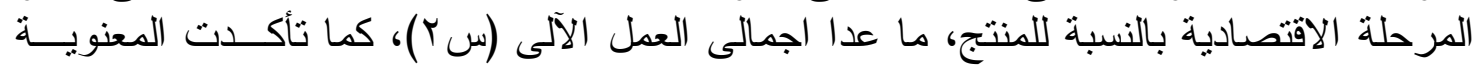

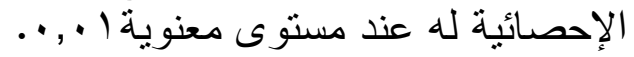




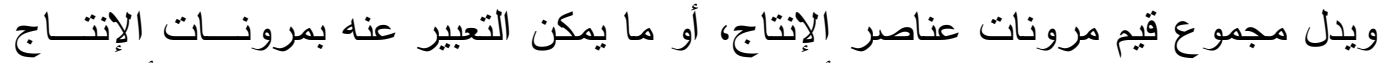

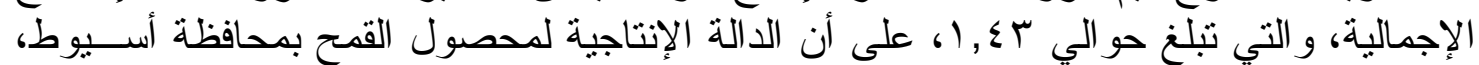

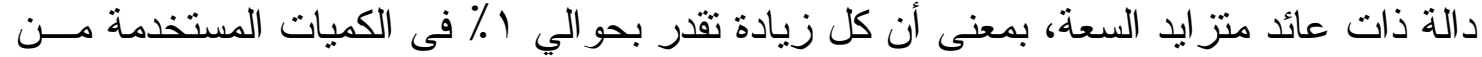

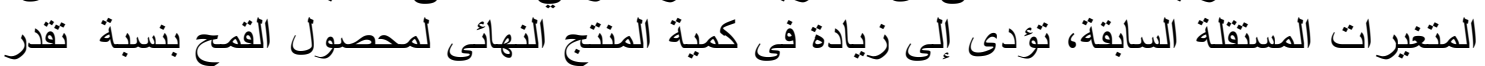

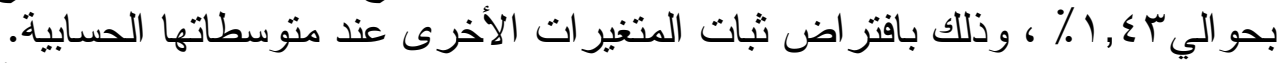

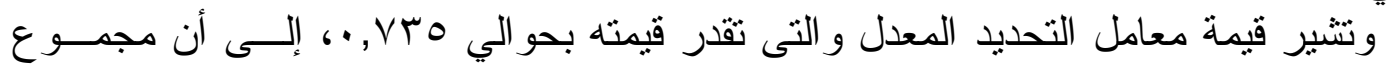

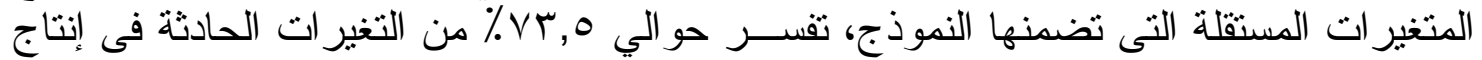

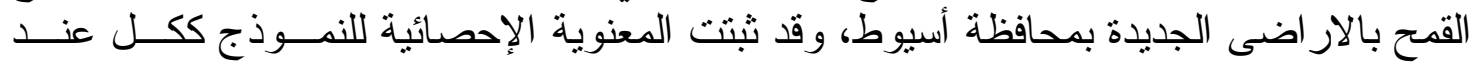

خامساً: التقدير الإحصائي لاوال تكاليف إنتاج القمح بعينة البحث فى محافظة أسيوط استخدمت البيانات المجمعة من عينة البحث لمحصول القمح فى محافظة أسيوط، فى تقدير دالة التكاليف الكلية، و التى تعبر عن العلاقة بين كمية الإنتاج الكلى بالاردب، وبين إجمالى قيمة

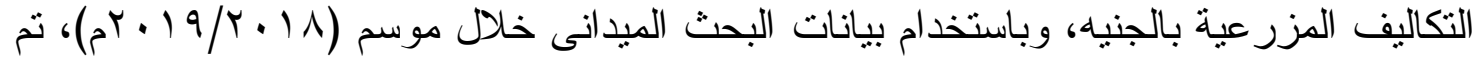

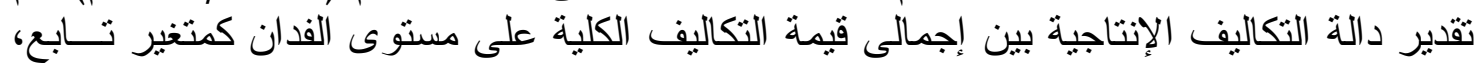
و إجمالى كمية إنتاج الفدان كمتغير مستقل، حيث تم استخدام النموذج التكعيبى، ليعبر عن العلاقة

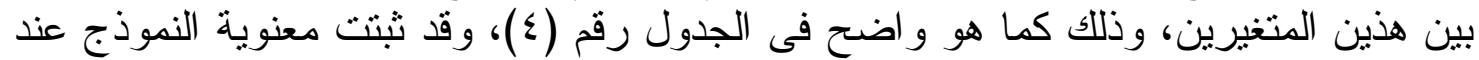

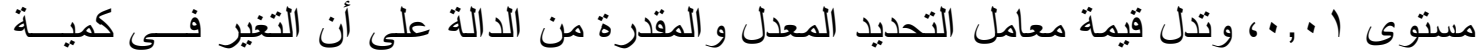

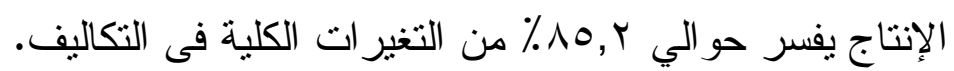

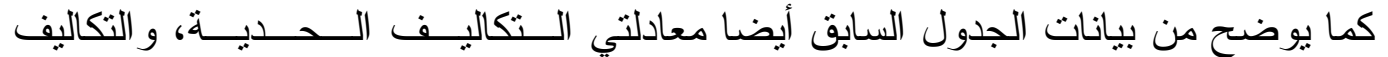

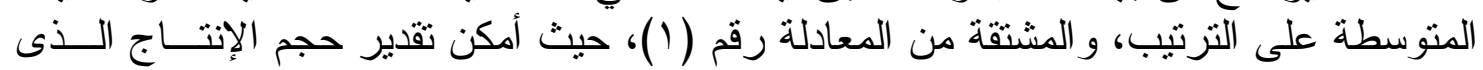

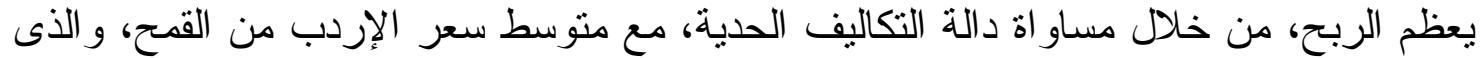

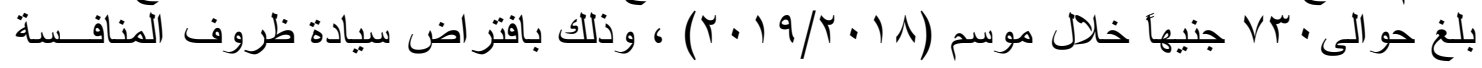

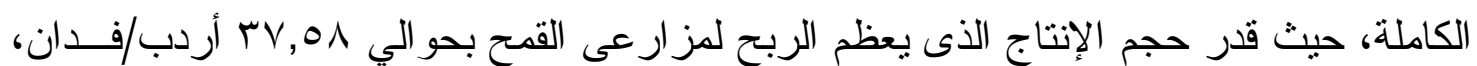

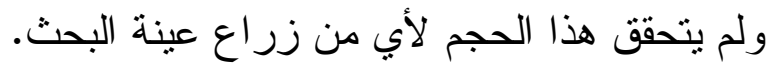

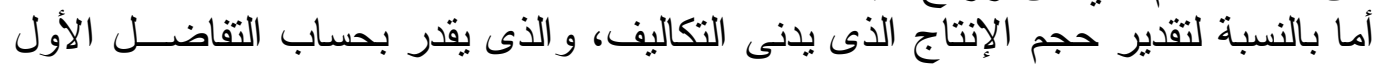

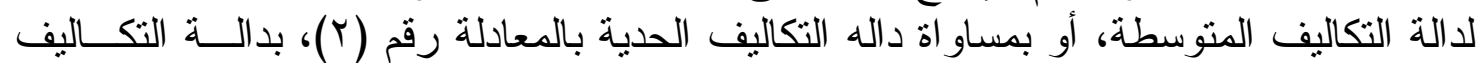
المتوسطة معادلة رقم (r)، وبفرض سيادة ظروف المنافسة الكاملة، فقد نبين أن حجم الإنتـاجـاج

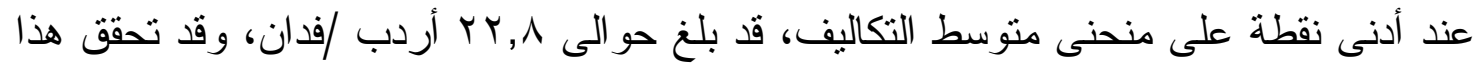

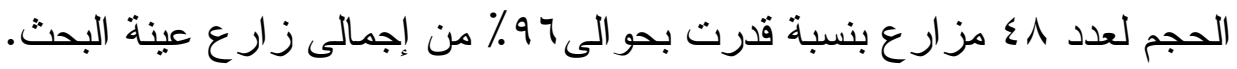




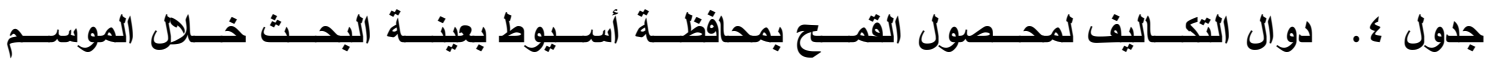

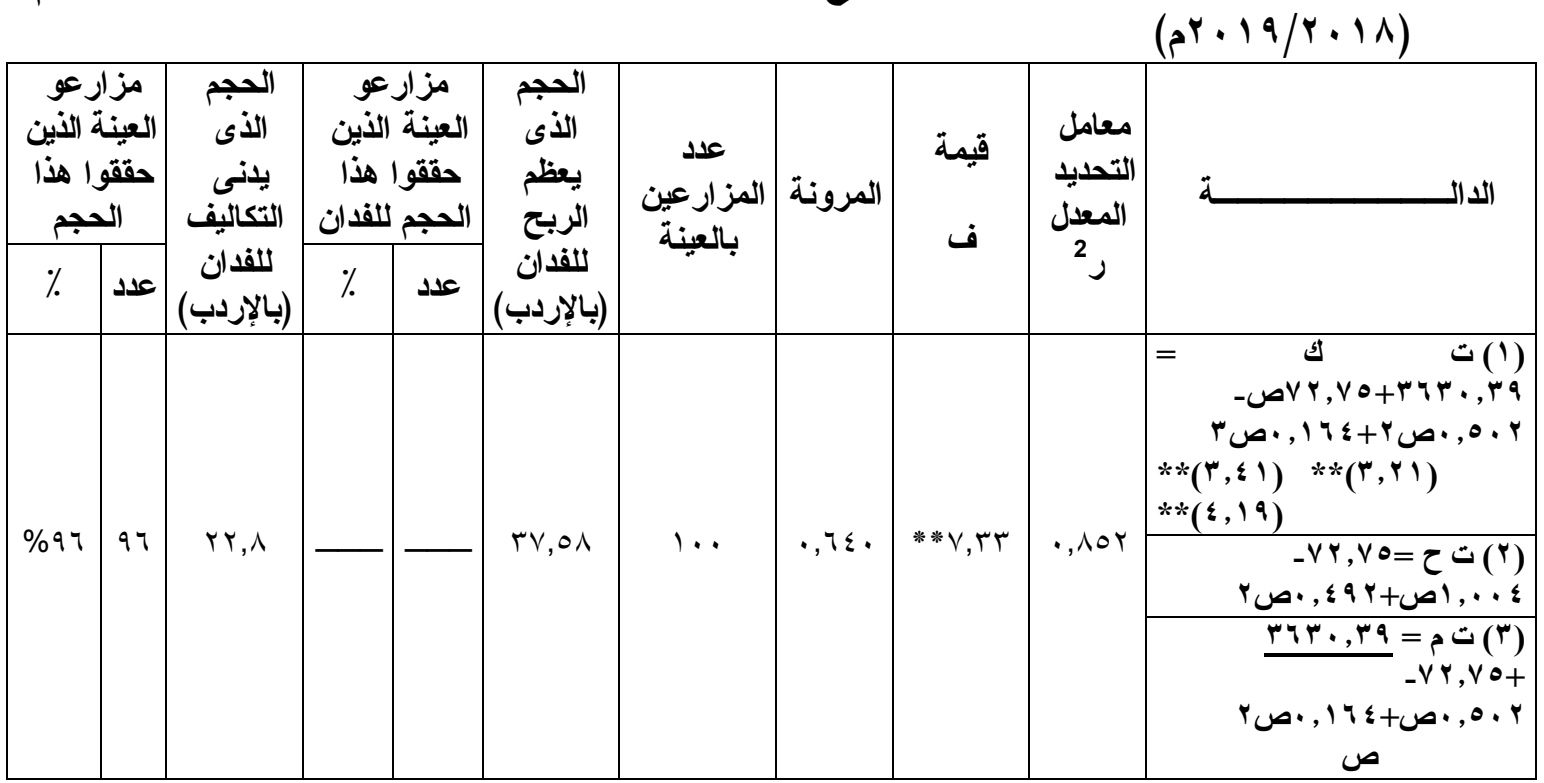

• ت ك ، ت م ، ت ح حتثير إلى كل من التكاليف الكلية و المنوسطة و الحدية على الترتيب.

. الأرقام ما بين القوسين تثبير إلى القيمة المحسوبة لاختبار (ت).

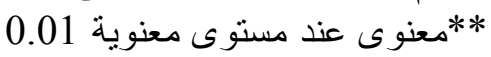

المصدر : جمعت وحسبت من استمارة الاستبيان.

جدول ه. مؤشر ات الكفاءة الاقتصادية لإنتاج محصول القمح بعينة البحث فى محافظة أسـيوط خــله

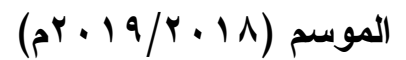

\begin{tabular}{|c|c|c|c|c|}
\hline \% الأتغير فى الجيدي & جديدة & قريمةً & 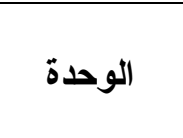 & المتغيرات \\
\hline$r \wedge, \varepsilon \vee$ & 10,71 & $r 1,9 Y$ & اردب & انتاج المحصول الرئيسىى \\
\hline$\cdot, \cdots$ & 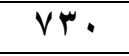 & Vr. & بالجنيه & سعر الناتج الرئيسى \\
\hline$Y \Lambda, \varepsilon \vee$ & $11 \leqslant \leqslant 4$ & $17 \ldots r$ & بالجنيه/فان & ايراد الناتج الرئيسى \\
\hline IY,O. & $v \ldots$ & $\Lambda \ldots$ & بالجنيه/فان & ايراد الناتج الثانوى \\
\hline YT,10 & $11 \leq \leqslant 4$ & $Y \leqslant \ldots r$ & بالجنيه/فانان & الاير اد الكلى \\
\hline Aq,ro & $9 \leqslant 1$ & 19.7 & بالجنيه/فانان & صافى العائد \\
\hline $9 \cdot, \wedge 1$ & •, &., 09 & بالجنيه/فان & اربحية الجنيه المستثر \\
\hline 10,11 & 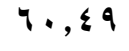 & \&. & بالجنيه/فان & اربحية الوحدة المنتجة \\
\hline
\end{tabular}

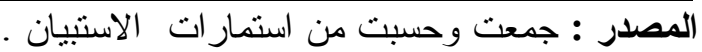

سادساً: مؤشر ات الكفاعة الاقتصادية لإتتاج محصول القمح بعينة البحث بمحافظة أسيوط:

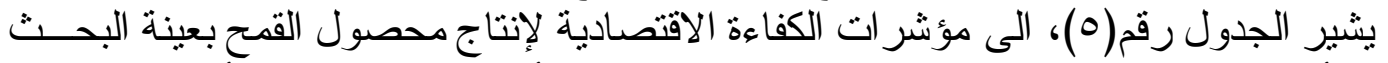

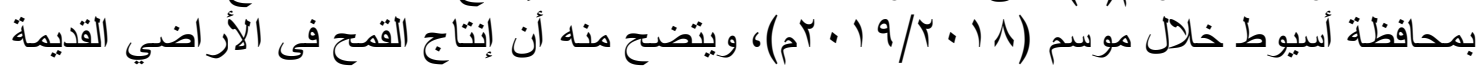

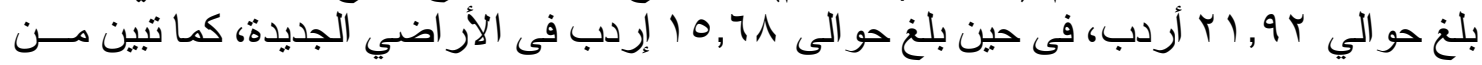

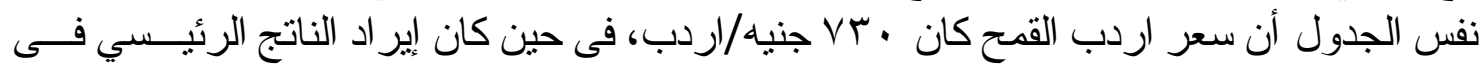

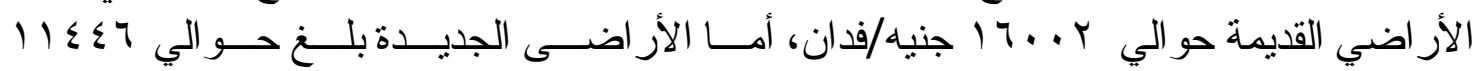

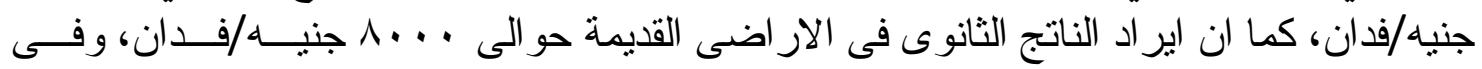




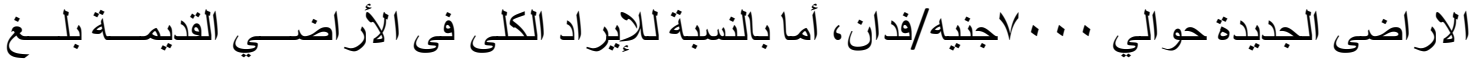

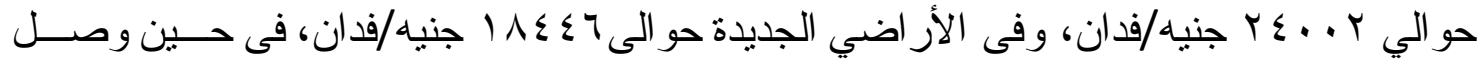

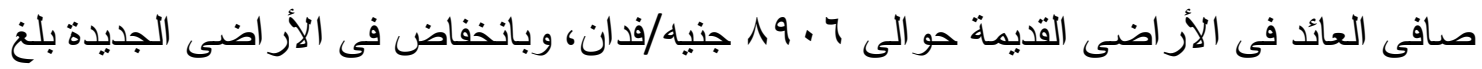

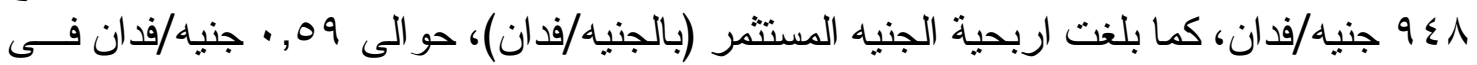

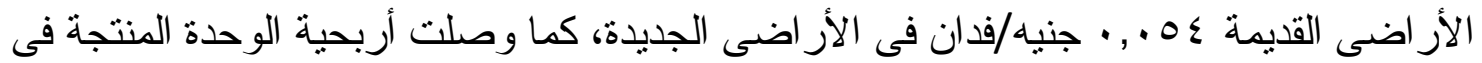

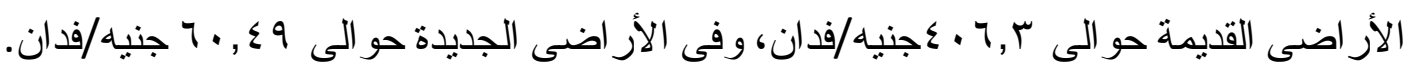

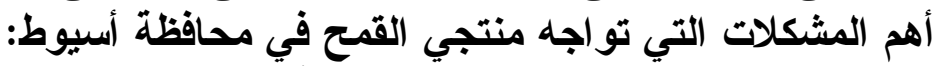

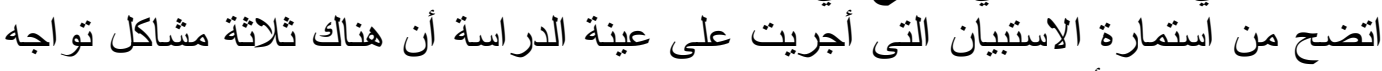

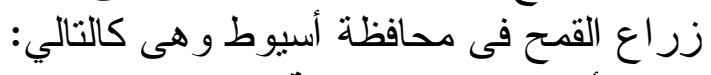

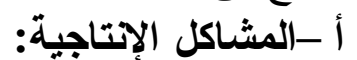

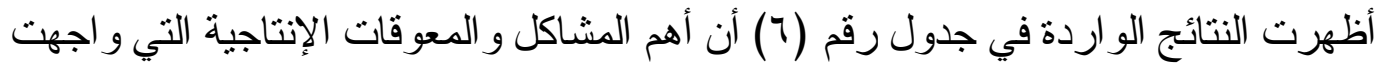

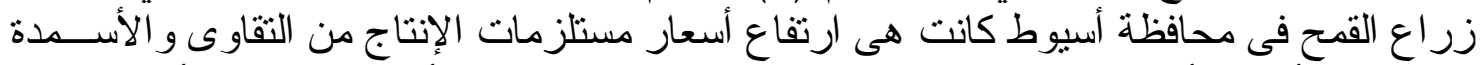

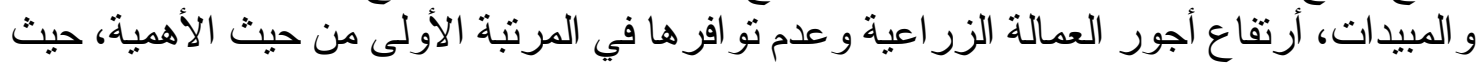

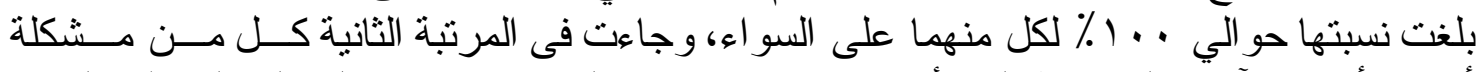

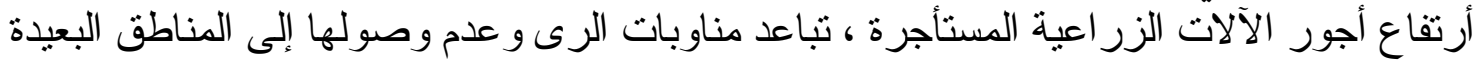

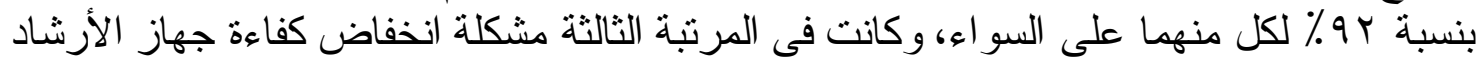

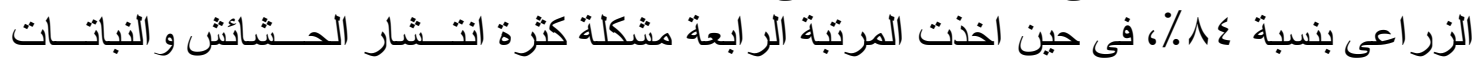

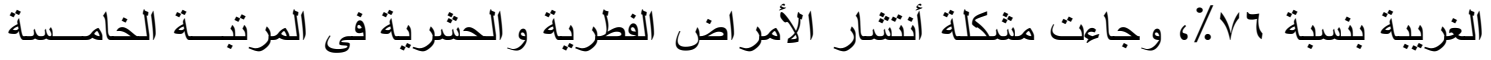

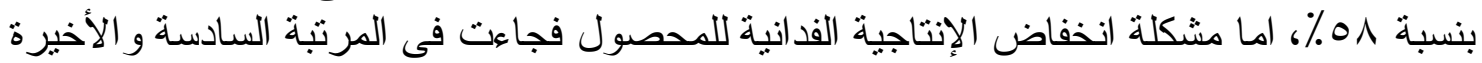

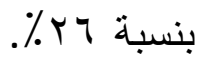

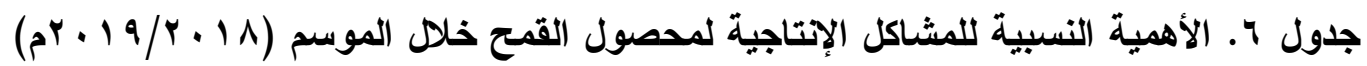

\begin{tabular}{|c|c|c|c|c|}
\hline الترتيب & ألعمالى من & 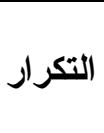 & 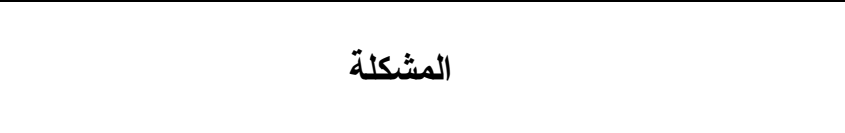 & 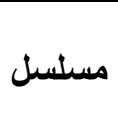 \\
\hline 1 & $1 \cdots$ & 0. & ارتفاع أسعار مستلزمات الإنتاج من التقاوى و الأسمدة و المبيدات & 1 \\
\hline 1 & $1 \ldots$ & 0. & أرتفاع أجور العمالة الزر اعية و عدم تو افر ها & r \\
\hline$r$ & $9 r, \ldots$ & $\varepsilon 7$ & أرتفاع أجور الآلات الزر اعية المستأجرة & $r$ \\
\hline r & $94, \cdots$ & $\sum 7$ & تباعد مناوبات الرى و عدم وصولها إلى المناطق البعيدة & $\varepsilon$ \\
\hline$r$ & $\wedge \varepsilon, \cdots$ & $\varepsilon r$ & أنخفاض كفاءة جهاز الأرشاد الزر اعى & 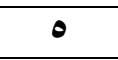 \\
\hline$\varepsilon$ & $\vee \vee, \cdots$ & rᄉ & كثرة أنتشار الحشائش و النباتات الغريبة & 7 \\
\hline 0 & $0 \wedge, \cdots$ & rq & أنتشار الأمر اض الفطرية و الحشرية & $\mathrm{V}$ \\
\hline 7 & $r\rceil, \cdots$ & $\pi$ & انخفاض الإنتاجية الفدانية للمحصول & $\Lambda$ \\
\hline
\end{tabular}

المصدر: جمعت وحسبت من بيانات استمارة الاسنبيان بعينة البحث.

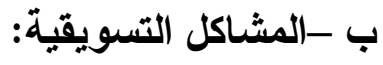

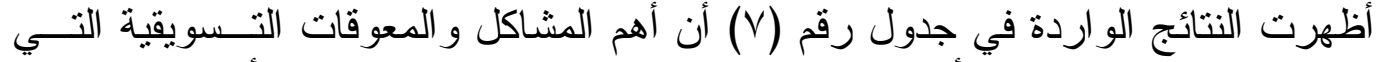

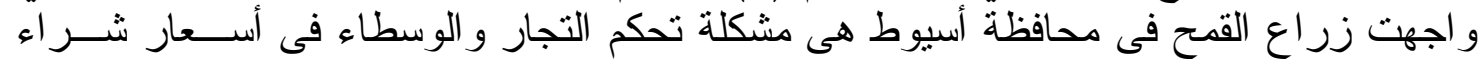

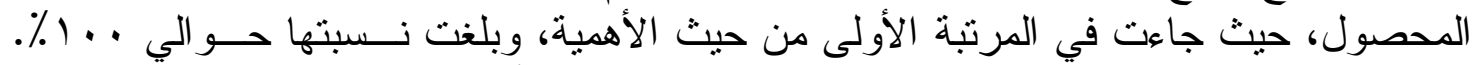

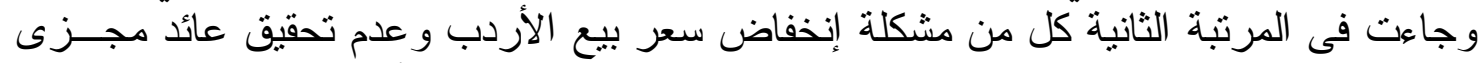

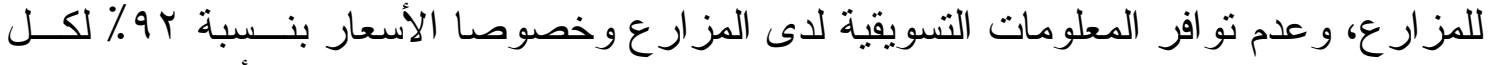

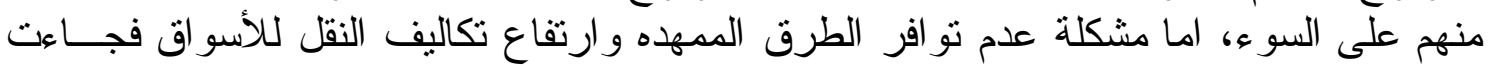




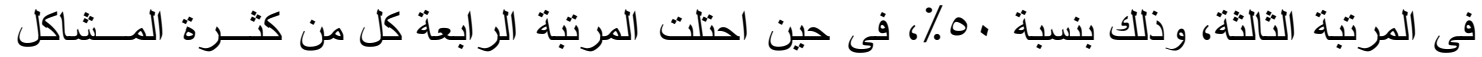

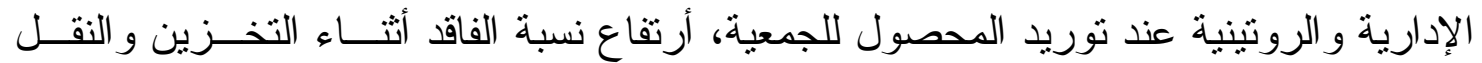

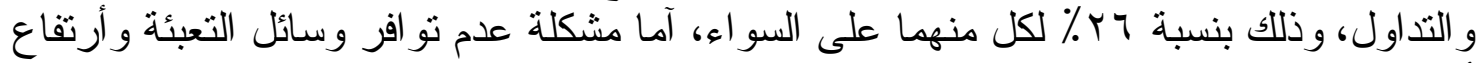

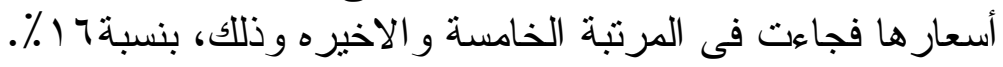

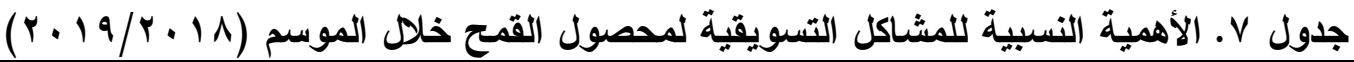

\begin{tabular}{|c|c|c|c|c|}
\hline الترتيب & اجمالى من & 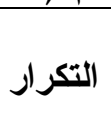 & 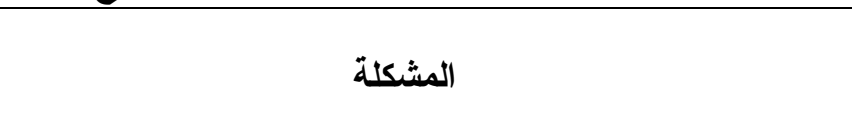 & 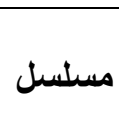 \\
\hline 1 & $1 \ldots$ & 0 . & تحكم التجار و الوسطاء في أسعار شر اء المحصول & 1 \\
\hline$r$ & $9 r, \cdots$ & $\sum 7$ & أنخفاض سعر بيع الأردب و عدم تحقيق عائد مجزى للمز ارع & r \\
\hline$r$ & $94, \cdots$ & $\leqslant 7$ & عدم تو افر المعلومات التسويقية لدى المزارع وخصوصا الأسعار & $r$ \\
\hline$r$ & $0 \cdot, \cdots$ & To & عدم تو افر الطرق الممهده وارتفاع تكاليف النقل للأسواق & $\varepsilon$ \\
\hline$\varepsilon$ & $r\rceil, \cdots$ & 14 & كثرة المشاكل الأدر اية و الروتينية عند توريد المحصول للجمعية & $\bullet$ \\
\hline$\varepsilon$ & $r 7, \cdots$ & $1 \pi$ & كثرة الخصو مات و الاستقطاعات من ثمن المحصول المورد & 7 \\
\hline$\varepsilon$ & $r 7, \cdots$ & $\pi$ & أرتفاع نسبة الفاقد أثناء التخزين و النقل و التداول & $\mathrm{V}$ \\
\hline 0 & $17, \cdots$ & $\Lambda$ & عدم تو افر وسائل التعبئة و أرتفاع أسعار ها & $\Lambda$ \\
\hline
\end{tabular}

المصدر: جمعت وحسبت من بيانات استمارة الاستيان بعينة البحث.

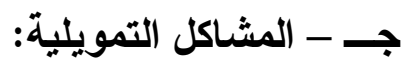

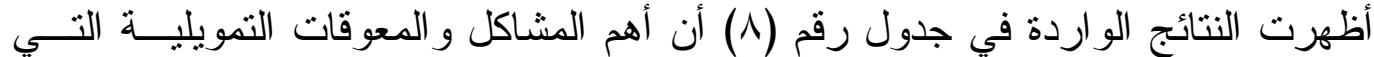

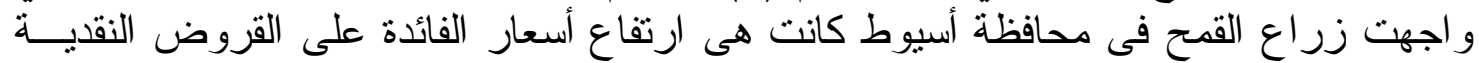

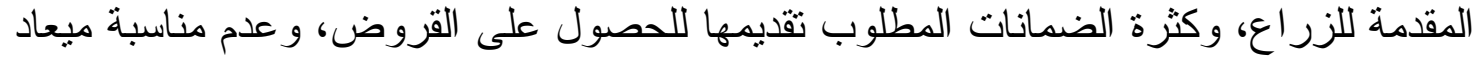

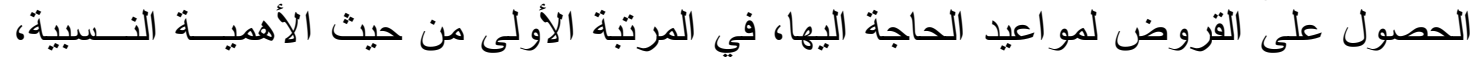

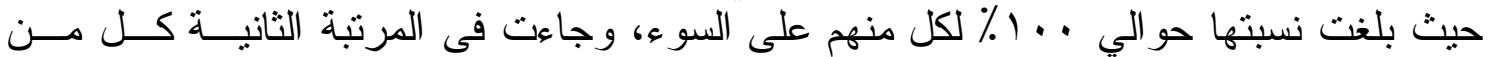

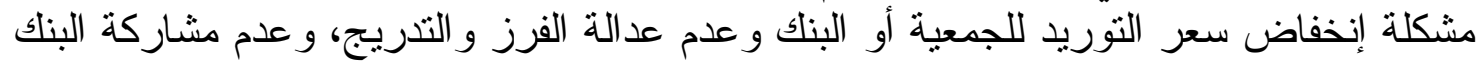

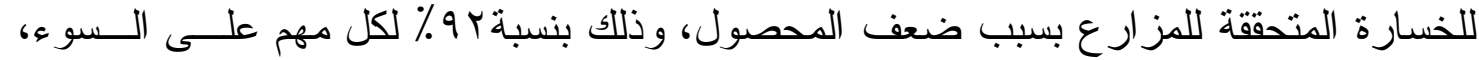

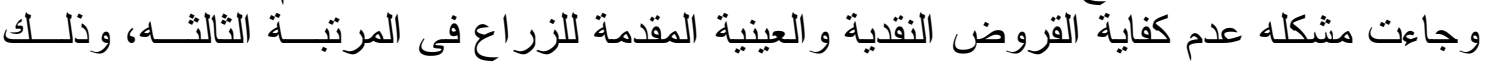

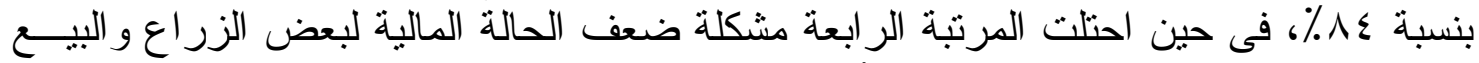

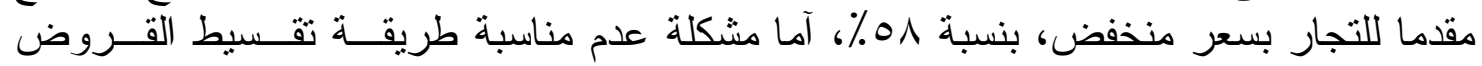

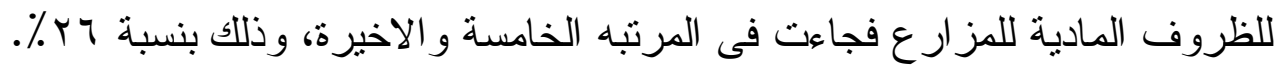

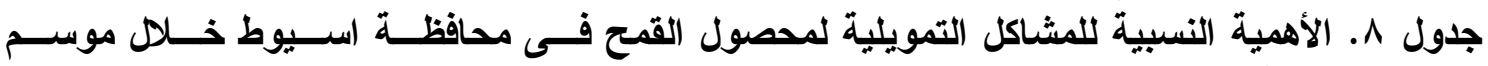

\begin{tabular}{|c|c|c|c|c|}
\hline الترتيب & أجمالى من & 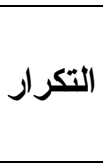 & 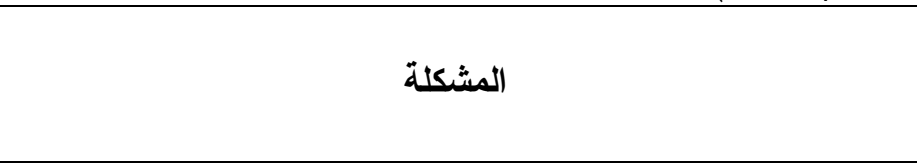 & 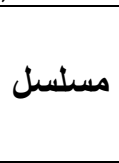 \\
\hline 1 & $1 \cdots$ & 0 . & ارتفاع أسعار الفائدة على القروض النقدية المقدمة للزر اع & 1 \\
\hline 1 & $1 \cdots$ & 0 . & كثرة الضمانات المطلوب تقديمها للحصول على القروض & r \\
\hline 1 & $1 \ldots$ & 0. & عدم مناسبة ميعاد الحصول على القروض لمو اعيد الحاجة اليها & $r$ \\
\hline$r$ & $94, \ldots$ & $\sum 7$ & أنخفاض سعر التوريد للجمعية أُو البنك و عدم عدالة الفرز و التدريج & $\varepsilon$ \\
\hline r & $94, \cdots$ & $\sum 7$ & عدم مشاركة البنك للخسارة المتحققة للمز ارع بسبب ضعف المحصول & $\bullet$ \\
\hline r & $\wedge \varepsilon, \cdots$ & $\varepsilon Y$ & عدم كفاية القروض النقدية و العينية المقدمة للزر اع & 7 \\
\hline$\varepsilon$ & $0 \wedge, \cdots$ & rq & ضعف الحالة المالية لبعض الزر اع و البيع مقدما للتجار بسعر منخفض & V \\
\hline 0 & $r 7, \cdots$ & 11 & عدم مناسبة طريقة تقسيط القروض للظروف المادية للمز ارع & $\Lambda$ \\
\hline
\end{tabular}


الملخص و التوصيات

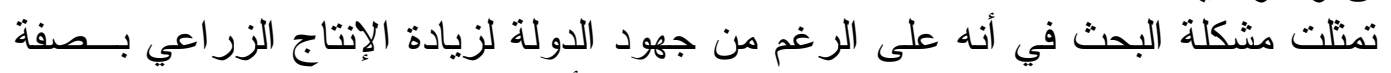

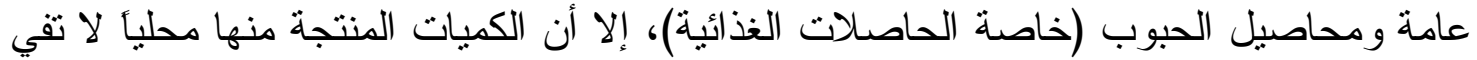

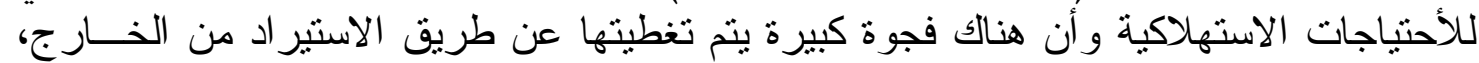

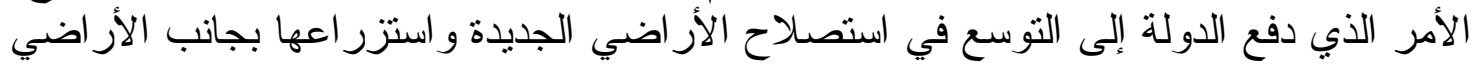

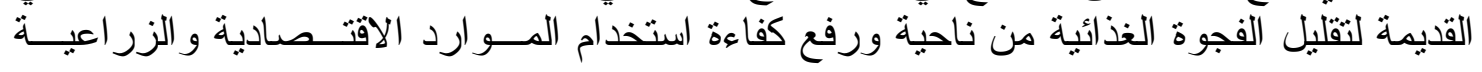
المستغلة في زر اعتها من ناحية أخرى.

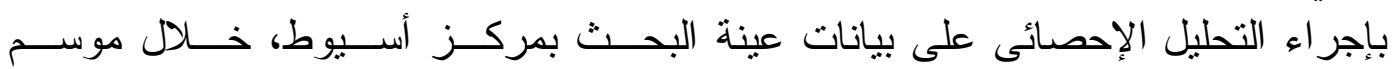

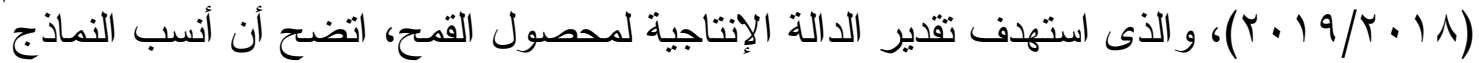

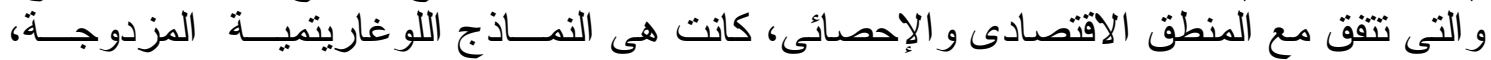

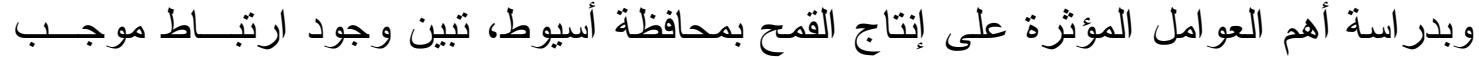

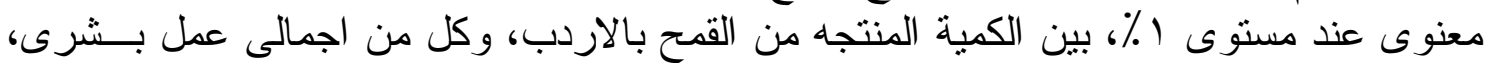

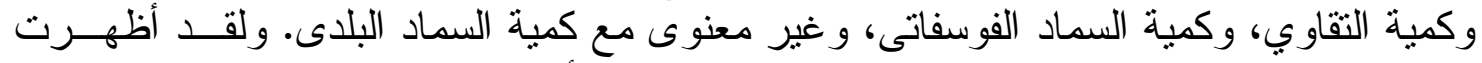

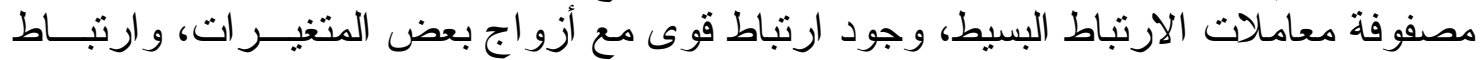

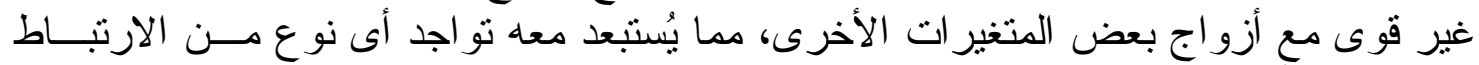

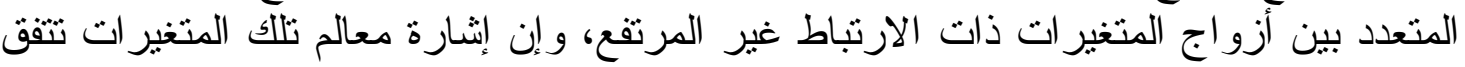

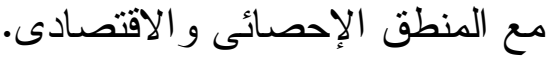
وبتقدير دالة التكاليف الإنتاجية تم الاستعانه بالنموذج التكعيبى قد ثبتت معنوية النمــوذج

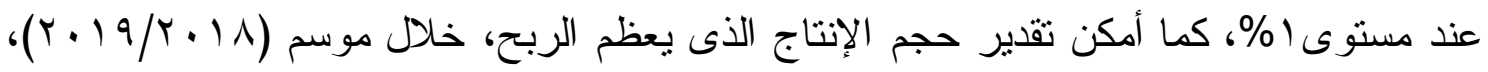

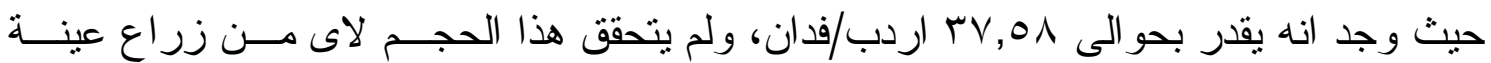

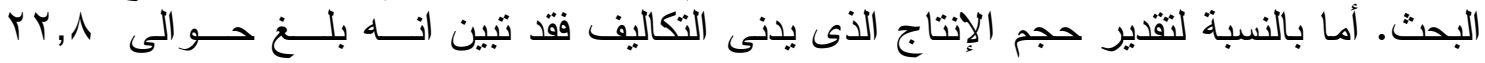

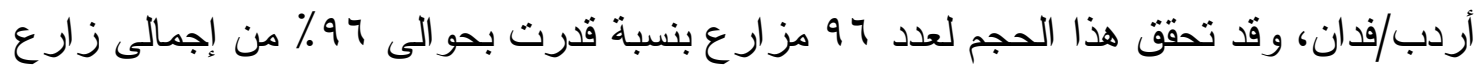

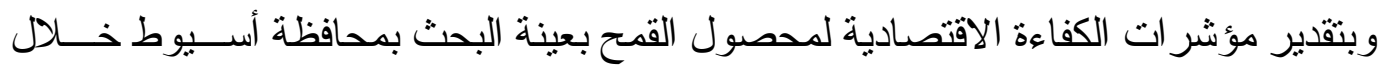

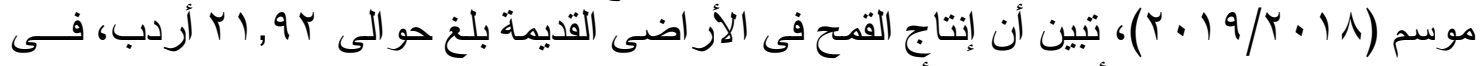

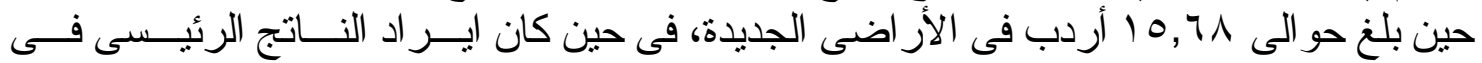

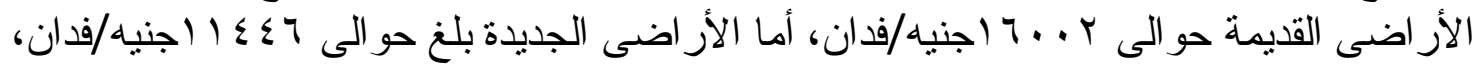

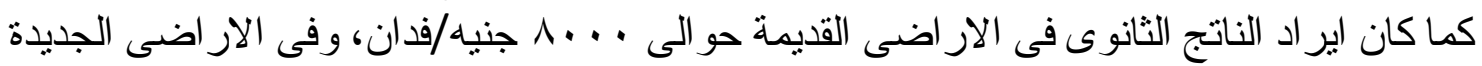

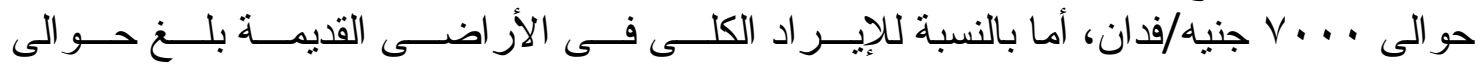

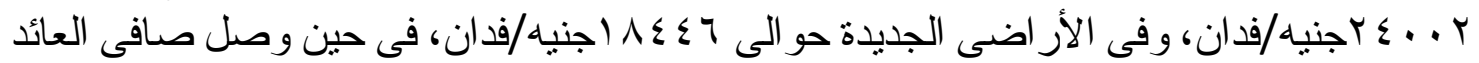

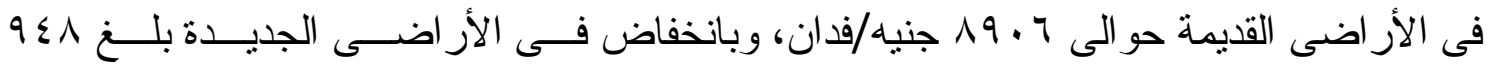

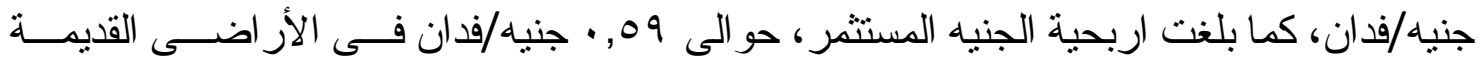

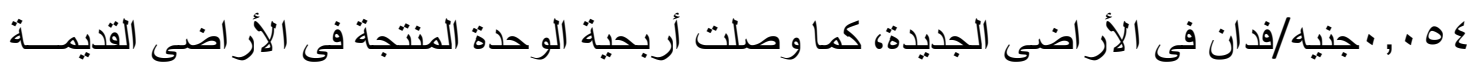

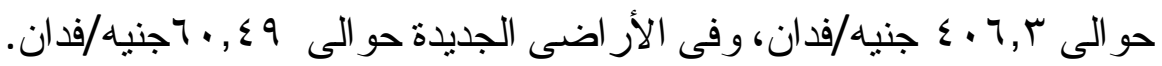
توصيات البحث: وفى ضوء ما تقدم من نتائج فأن الدر اسة توصى بما يلي:

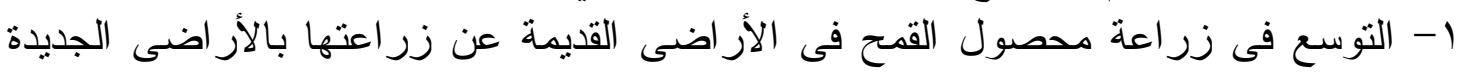
بمحافظة أسيوط. 
r- زيادة فعالية دور جهاز الإرشاد الزراعى بالأر اضى الجديدة بالمحافظة لتوعية و إرشاد

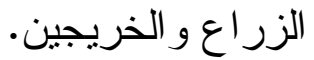
r- توفير المنافذ التسويقية التعاونية لتسويق المنتجات الزر اعية بالأراضى الجديدة لتقليل الفاقد

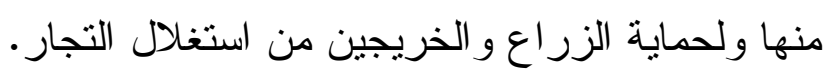

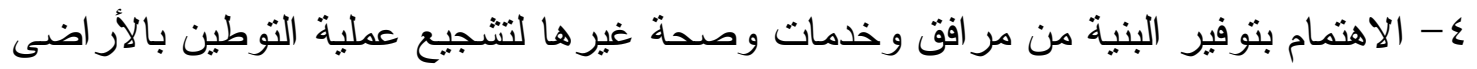

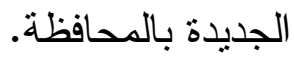
0- حصول الخرجيين و الزراع على القروض القراع النقدية الكافية وبأسعار فائدة مناسبة مع تيسير

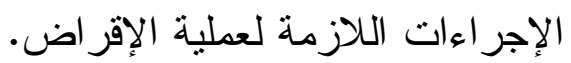

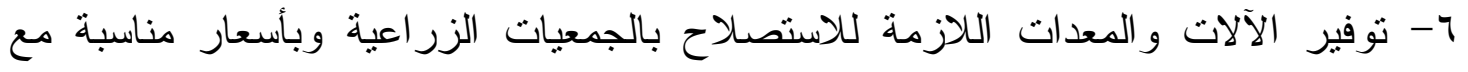

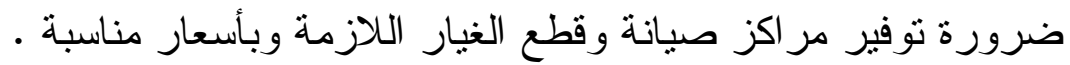

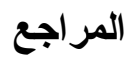

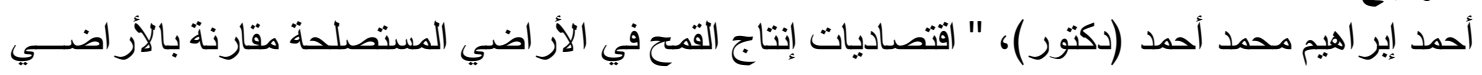

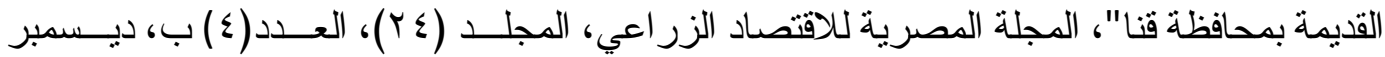
.r. $1 \leq$

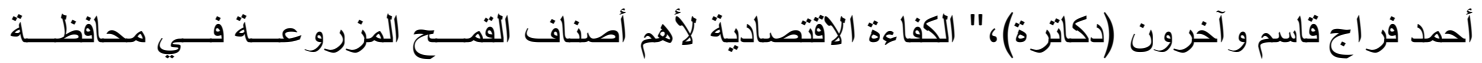

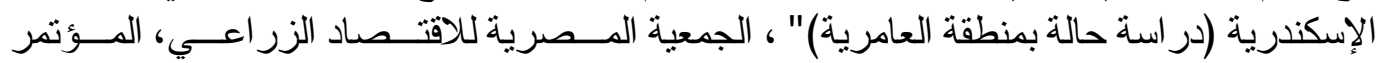

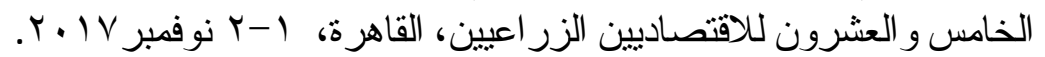

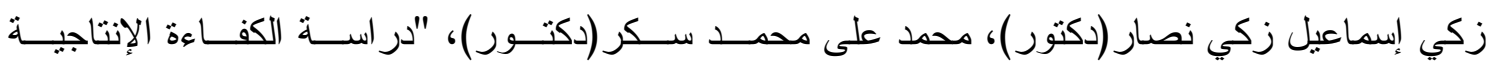

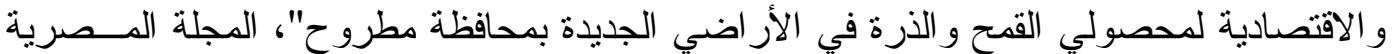

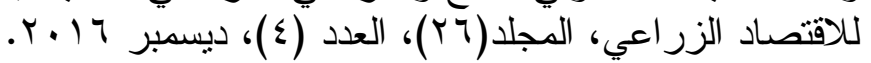

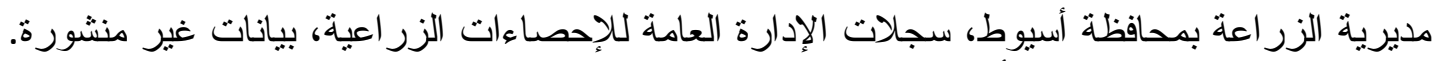

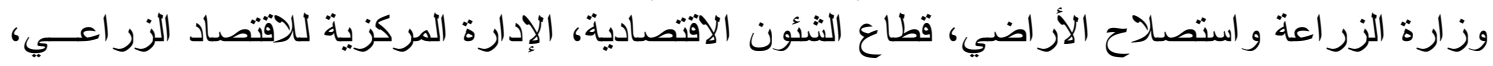
نشرة الإحصاءات الزر اعية. 


\title{
The Functions of Production and Costs of the Wheat Crop and the Most Important Problems of Agricultural in Assiut Governorate
}

\author{
Abdallah Helmey Abdelghney; Galal Abd Elfattah Elsagheer; Suzan AbdAlma- \\ jeed Abo Almaj; Yahya Ali Hussein Khalil and Salah Ali Salh Fadlallah
}

Department of Agricultural Economics, Fac. Agric., Assiut University

\section{Summary}

The research dealt with a study of the effect of production requirements on some food crops in Assiut Governorate by identifying the most important agricultural crops in Assiut Governorate, where wheat and maize crops are among the most important food crops in Egypt in general and Assiut Governorate in particular, as the total area planted with wheat crops in Egypt in the year 2018/2019 is about 3157 thousand feddans, and in Assiut Governorate about 222 thousand feddans, representing about $7 \%$ of the total area cultivated with the wheat crop in Egypt in the same year, and the yield per feddan of the crop in Egypt was about 17.7 ardeb / feddan.

In Assiut governorate about 17.4 ardeb / feddan (representing about $98 \%$ of that in Egypt in the same year), and the total production of the crop in Egypt was about 55,658 thousand ardebs, and in Assiut the total production reached about 3,863 thousand ardebs (representing about $7 \%$ of Total total production of the crop in Egypt in the same year), and similarly, the total area cultivated with the maize crop in Egypt in 2018/2019 amounted to about 1,489 thousand feddans, and in Assiut Governorate about 128 thousand feddans, representing about 8.6\% of the total area cultivated by the crop in Egypt in the same Year, The research problem was that despite the state's efforts to increase agricultural production in general and grain crops (especially food crops) in most governorates of the Republic, whether old lands or new and reclaimed lands, the locally produced quantities do not meet consumer needs and that there is a large gap that is covered. By importing from abroad, the research mainly aimed at researching the productive and economic efficiency of some agricultural crops in Assiut Governorate (for wheat and maize crops).

It was possible to estimate the volume of production that maximizes profit, by equating the marginal cost function with the average price of wheat, which amounted to about 730 pounds during the season (2018/2019), assuming the prevalence of conditions of perfect competition, as the volume of production that maximizes profit was estimated The wheat grower is about 37.58 ardeb/ feddan, and this size was not achieved by any of the farmers of the research sample.

A necessity research is recommended:

1- Expanding the summer crops of wheat and maize in the old lands, and reducing the cultivated area of summer wheat and maize crops in the new lands in Assiut Governorate.

2- Increasing the effectiveness of the role of the agricultural extension agency in the new lands in the governorate to educate and guide farmers and graduates to the best methods of service and agricultural operations and to choose crops that are suitable and present in the new lands in the governorate. 